\title{
KODAK CANADA: INCREASING ACCESS TO ADVERTISING MATERIALS IN RYERSON UNIVERSITY LIBRARY'S SPECIAL COLLECTIONS
}

by

Keri Lee Kauffman

Bachelor of Arts in Art, Eastern Mennonite University, Harrisonburg, Virginia, December 2000

\author{
A thesis \\ presented to Ryerson University and George Eastman House International Museum of \\ Photography and Film \\ in partial fulfillment of the \\ requirements for the degree of \\ Master of Arts \\ in the Program of
}

Photographic Preservation and Collections Management

Toronto, Ontario, Canada, 2009

(C) Keri Lee Kauffman 2009 
I hereby declare that I am the sole author of this thesis or dissertation.

I authorize Ryerson University to lend this thesis or dissertation to other institutions or individuals for the purpose of scholarly research.

I further authorize Ryerson University to reproduce this thesis or dissertation by photocopying or by other means, in total or in part, at the request of other institutions or individuals for the purpose of scholarly research. 
"Kodak Canada: Increasing Access to Advertising Materials in Ryerson University Library's Special Collections"

Master of Arts in Photographic Preservation and Collections Management, 2009

Keri Lee Kauffman

Photographic Preservation and Collections Management, Ryerson University and George Eastman House International Museum of Photography and Film

Abstract:

In 2005, amidst declining sales of film-based photographic materials, Kodak Canada Inc. ceased manufacturing operations at its Toronto headquarters. Before the property's sale, the material in its corporate archive and employee museum was donated and removed to Ryerson University, where it became the keystone of Ryerson University Library's newly established Special Collections department.

While some Kodak Canada material has been processed and utilized in displays and other forms of presentation, the advertising collection - ordered chronologically from 1922 to 1987 in heavy ledger books, but not catalogued at item level - has remained largely untouched. This project's goal has been to create avenues of access to this portion of the Kodak Canada Heritage Collection through its cataloguing and digitization, and to facilitate its presentation on a Special Collections website. The following pages present the historical background of Kodak Canada and the advertising collection, provide reference data, and describe the practical methodologies applied to the project. 


\section{Acknowledgments:}

My work with the Kodak Canada advertising collection would not have been possible without the support of Elizabeth Knazook, Photographic Specialist for Ryerson University Library's Special Collections, and Robert Burley, Associate Professor at Ryerson University's School of Image Arts and my thesis advisor. Their advice and flexibility enabled me to take on an ambitious project and complete it successfully. My sincere gratitude also goes to Bruce Horsburgh and Michael Derblich, both former employees of Kodak Canada Inc. with long careers in its Communications Department, whose time and energy helped me contextualize the advertising collection's history and use.

Thanks also to Susan Patrick, Special Collections Librarian, and Trina Grover, Head of Cataloguing for promptly answering questions and giving advice when called upon. Further thanks go to Kathy Connor, Curator of the Eastman Legacy Collection at George Eastman House International Museum of Photography and Film in Rochester, New York, for helping me understand the arrangement and use of that institution's Kodak Advertising Collection, and to Dr. Alison Nordstrom, Curator of Photographs at George Eastman House, for her guidance during the formative stages of proposals and project planning.

Finally, I am sincerely grateful for the assistance provided by the Social Sciences and Humanities Research Council of Canada (SSHRC); without the support of their Joseph-Armand Bombardier CGS Master's Scholarship, this endeavor would not have been possible. 


\section{Table of Contents}

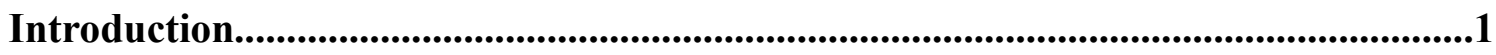

Chapter 1: Literature and Resource Survey...........................................................................3

Chapter 2: History and Significance..........................................................................................6

Canadian Kodak Company, Limited and Kodak Canada Inc. 6

$\begin{array}{ll}\text { Ryerson University Library Special Collections } & 10\end{array}$

Kodak Canada Heritage Collection: Advertising Ledgers 12

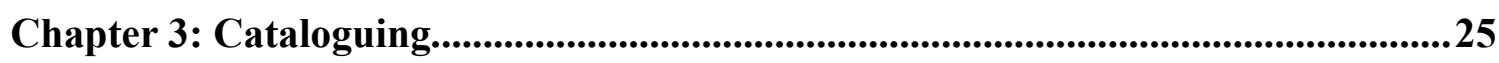

$\begin{array}{ll}\text { Goals } & 25\end{array}$

$\begin{array}{ll}\text { Cataloguing Practice and Format } & 26\end{array}$

$\begin{array}{ll}\text { Issues and Considerations } & 28\end{array}$

Chapter 4: Digitization................................................................................................................32

$\begin{array}{ll}\text { Goals } & 32\end{array}$

Digitization Practices and Standards 33

$\begin{array}{ll}\text { Issues and Considerations } & 35\end{array}$

Chapter 5: Website Planning...................................................................................................39

$\begin{array}{ll}\text { Goals } & 39\end{array}$

$\begin{array}{ll}\text { Key Features } & 40\end{array}$

Copyright and Restrictions of Use 41

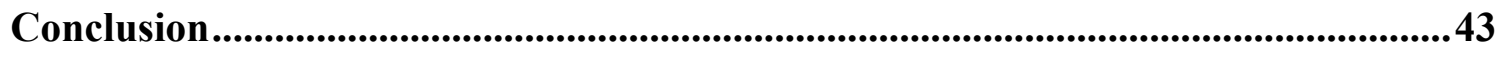

Appendix A: Catalogue Field Definitions...........................................................................46

Appendix B: Example Catalogue Records....................................................................47

Appendix C: Scanner and Digital Image Specifications..................................................... 49

Appendix D: Example Images with Catalogue Records....................................................51 
Appendix E: Suggested Website Architecture and Page Mockups..............................55

Bibliography.........................................................................................................................58

Websites and Online Resources............................................................................60 


\section{Introduction}

In 2005, amidst declining sales of film-based photographic materials, Kodak Canada Inc. ceased manufacturing operations at its Toronto headquarters. As the company prepared to vacate and sell the property, it was arranged that the material in its archive and employee museum would be donated to Ryerson University. Several faculty and staff members and students from Ryerson University's Photographic Preservation and Collections Management master's program visited the site to organize and remove the material as the date of the property's sale approached. The resulting collection included photographic prints, negatives, cameras and equipment, publications, documents and company advertisements, and was housed in the Ryerson University Library. Now officially titled the Kodak Canada Heritage Collection, this corporate archive formed the keystone of the library's Special Collections department, which was established in late 2006 .

Some prints, cameras and other equipment from the collection have been catalogued and used for displays and other presentations. The advertising collection - made up of thirty-three ledger books and spanning the years 1922 to 1987 - could be of interest to researchers in a variety of fields, however it has remained largely untouched. The printed advertisements are grouped into the ledger books chronologically but not catalogued at item level, and the weight and awkward size of the books make browsing their pages a daunting proposition.

In addition, the tape that once held many of the advertisements to their ledger pages has become dry and ineffective with age, causing the prints to float loosely within the heavy books, contributing to the overall vulnerability of the collection. Any movement of these books, including the shifting that naturally occurs in their upright storage in Special Collections, 
threatens additional damage to the prints inside, compounding preservation concerns already present due to the non-archival nature of their surrounding materials.

Given these circumstances, the goal of my project is to create alternative avenues of access to advertisements in the Kodak Canada Heritage Collection through digitization and the creation of effective catalogue records, with a plan for future web-based presentation. In this way, I hope to provide a structured delivery of information that encourages remote access to these objects and their related metadata by researchers from a variety of fields, allowing the advertisements to "live" without compromising the preservation of the original objects.

Due to the large number of advertisements in the collection, I chose to focus my work on two ledger books, representing ads from several important points in US and Canadian history: 1922-23, representing the earliest ads in the collection, and 1936-37, which provides insight into advertising strategies used during the Great Depression.

In the proceeding pages, I will present a response to the literature available on this topic, and will also outline brief histories of the Kodak Canada corporation, the advertising collection itself, and Ryerson University Library's Special Collections. In addition, I will explain in detail the cataloging and digitization methods used for the project. The final sections include suggestions for the structured delivery of collection and object information through a website, as well as my conclusions and estimates for structuring future work with the collection. Finally, the appendices provide a series of tables and figures referenced in the interceding chapters, website architecture and wireframe page diagrams, and representative examples of the practical output of my work. 


\section{Chapter 1: Literature and Resource Survey}

During my research, I discovered very little published material relating directly to the content of the Kodak Canada advertising collection. Many of the written "histories" of Kodak Canada Inc. available today are brief pieces published in aging periodicals or reports, or by the company itself in its own publications, thoroughly vetted by those in charge of public relations. Below are reviews of several of these short corporate biographies, which I referenced to shape my own overview of the company's history. A future researcher might use such materials - plus, perhaps, other papers and publications in the Kodak Canada Heritage Collection - to craft a more lengthy and thoughtful analysis of the company's history and its role in helping shape modern Canadian consumer culture.

Photographic Canadiana is the journal of the Photographic Historical Society of Canada, published five times a year since 1974 for the group's members. Its 1976 issues provided a twopart history of Kodak Canada derived from a company pamphlet and from a speech given in 1975 by the company's Supervisor of Communications, R.G. Morrison. ${ }^{1}$ Although it was written thirty years before the downsizing that would bring an end to the corporate headquarters at Kodak Heights, this history provides a valuable narrative of the formation and subsequent development and growth of Canadian Kodak Company Limited. The journal's limited publication makes it more difficult to locate than some other resources; however, back issues of the periodical can be accessed at the Toronto Public Library, George Eastman House in Rochester, New York, the New York Public Library, and the Library and Archives Canada in Ottawa, Ontario, among other locations.

\footnotetext{
${ }^{1}$ R.G. (Bud) Morrison, "The History of Kodak Canada Ltd." and "The History of Kodak Canada Ltd.," Photographic Canadiana Vol. 1 Nos. 7 and 8 (1976): 1-3 and 4-6.
} 
In the winter of 2005, four master's students in Ryerson University's Photographic Preservation and Collections Management program completed a thorough report on the acquisition and initial processing and arrangement of the Kodak Canada archive as it was brought into the university's collection. ${ }^{2}$ Never formally published, this report - titled The Kodak Canada Archive and Heritage Collection at Ryerson University - contains another historical overview of Kodak Canada, as well as useful documentation of the discussions surrounding the arrangement of the incoming material. The appendices provide an inventory of the entire collection, a thorough record of the camera collection in particular, and lists of resources for further reference. Only a few copies of this report exist, one of which is kept in Special Collections and can be accessed for reference purposes.

The Kodak Salesman, published monthly from at least 1917 through 1942 for Canadian dealers of the company's products, contains short articles and promotional pieces designed to help merchants increase the sales of cameras and film. While I am unaware of any comprehensive index of the periodical's contents, browsing the issues from a certain year can provide valuable insight into the corporate and commercial developments of that time. For instance, articles from the September 1921 and July 1922 issues provided valuable detail for my section on the history of Canadian Kodak Co., Limited, which begins in Chapter 2 on page 6. In addition, many issues contain example advertisements with accompanying explanations of Kodak Canada's seasonal marketing campaigns, ad distribution, and tips for storeowners to use related visual material to increase sales. Several features of this nature are included as examples in the section describing the history of the advertising collection (Chapter

\footnotetext{
${ }^{2}$ A Report: The Kodak Canada Archive and Heritage Collection at Ryerson University, by Jessica McDonald et al (Toronto: Ryerson University, 2005).
} 
2, page 12). This insight into the company's interpretation of the consumer market and the intent and scope of specific advertising campaigns is invaluable, and could be used at much greater depth to analyze the cultural context and significance of particular elements of the Kodak Canada advertising collection.

While the American version of The Kodak Salesman is available in several libraries across the United States, I was able to locate a record of Canadian issues only in Ryerson University Library's Special Collections. However, the complete volumes for the years 1917-1918, 1919-1920, 1921-1922, and 1923 have been digitized and made available online through the Internet Archive, for viewing or downloading as PDF files. ${ }^{3}$

The retelling - or revisioning - of Kodak's story has, at times, been frustrated by the tight rein Eastman Kodak keeps over its history, public image and brand legacy. To help overcome this scarcity of published information, my research included correspondence with several former employees of Kodak Canada's communications department. I also made contact with curators working with other archives of Kodak advertising material, namely the Eastman Legacy Collection at George Eastman House in Rochester, New York and the Kodak Australasia archive at Museum Victoria in Melbourne, Victoria, Australia. The recent closure of many of Eastman Kodak's international operations - and the resulting dispersal of archival material amongst a variety of international caretakers - has created an opportunity for increased international and inter-institutional communication.

\footnotetext{
3 These issues can be accessed and downloaded by visiting the Internet Archive's website at http://www.archive.org and searching for "Kodak Salesman."
} 


\section{Chapter 2: History and Significance}

\section{Canadian Kodak Company, Limited and Kodak Canada Inc.}

In 1898, George Eastman sent a new employee - John G. Palmer - to Toronto, Ontario to assess the market potential for a Canadian subsidiary of Eastman Kodak. By that time, Eastman's revolutionary flexible roll film had already been on the consumer market for almost 10 years. While the photographic goods manufacturer had opened several branch offices and manufacturing plants overseas in England and France, it continued to serve its respectably sized Canadian market through a small group of traveling sales representatives who carried orders and goods back and forth from Rochester, New York. When Palmer returned from Toronto with a positive assessment of Canadian market prospects, Eastman quickly sent him back across the border with the task of creating a full-fledged Canadian subsidiary. ${ }^{4,5}$

Canadian Kodak Company, Limited began its commercial existence with ten employees in a rented building on Colborne Street in downtown Toronto. After only a few years, business had grown enough to warrant the company building its own, larger space, which it did on King Street West. ${ }^{6}$ As early as 1913, however, the business's growing employee base and rapidly increasing sales made necessary yet another move. A 23-acre property was obtained northwest of downtown Toronto at the intersection of Weston Road and Eglinton Avenue, and the construction of the buildings at Kodak Heights began. ${ }^{7}$ At the time of John G. Palmer's death in

\footnotetext{
${ }^{4}$ Kodak, "History of Kodak: Milestones - Chronology, 1878-1929," Kodak, http:/www.kodak.com/global/en/corp/ historyOfKodak/1878.jhtml?pq-path=2699.

${ }^{5}$ R.G. (Bud) Morrison, “The History of Kodak Canada Limited,” Photographic Canadiana Vol. 1 No. 7 (1976): 1.

${ }^{6}$ Ibid., $1,2$.

${ }^{7}$ Ibid., 2-3. The size of the property and foresight in building planning would allow many of these structures to be continuously used and, at times, expanded, until the company's restructuring efforts eliminated most of its manufacturing processes at the turn of the twenty-first century.
} 
August 1921, the Canadian company employed over 1,000 workers at Kodak Heights - a

remarkable increase from the ten that opened the offices on Colborne Street twenty years earlier. ${ }^{8}$

The extended property included its own power plant and water system, as well as a paper and box factory and other production and maintenance facilities. ${ }^{9}$

Over the following decades, Canadian Kodak steadily increased its manufacturing presence and became an international supplier of photographic paper and other materials. It also became involved in war efforts, dedicating one of its buildings for a military barracks during World War I, and supplying people, materials such as microfilm and chrome plating, and several manufacturing processes to support the Allied effort during World War II. ${ }^{10}$

By the middle of the twentieth century, more acreage had been added to Kodak Heights, and major building expansion and renovations were planned to allow room for continued growth. ${ }^{11}$ This construction included an 'Employees' Building” that was dedicated to providing the workers with facilities for extracurricular use. The new building included a photography studio and darkrooms, in addition to a gymnasium, cafeteria, dining area and other amenities meant to improve (or maintain) employee satisfaction and quality of life. ${ }^{12}$

When the rise in popularity of colour consumer photography made necessary the creation of dedicated colour film processing facilities in 1961, the need for increased space led to a

\footnotetext{
8 “Mr. John G. Palmer,” The Kodak Salesman Vol. 7 No. 8 (September 1921): 3.

9 “About Ourselves,” The Kodak Salesman Vol. 8 No. 6 (July 1922): 15.

${ }^{10}$ R.G. (Bud) Morrison, “The History of Kodak Canada Limited - Concluded," Photographic Canadiana Vol. 1 No. 8(1976): 5 .

11 Ibid., 5.

12 Jessica S. McDonald, "Part I: Kodak Canada: History of the Company and the Collection," in A Report: The Kodak Canada Archive and Heritage Collection at Ryerson University, by Jessica McDonald et al (Toronto: Ryerson University, 2005), 4.
} 
corporate decision to build the new facilities in North Vancouver, British Columbia - the first Canadian Kodak plant to be built outside the Toronto area. ${ }^{13}$ In 1971, Canadian Kodak merged with several other, related subsidiaries of the Rochester parent corporation to become Kodak Canada Incorporated. By this time, additional properties had also been added near Brampton, Ontario and Montreal, Quebec. By 1974, Kodak Canada's employee base had grown to about 2700 individuals. ${ }^{14}$

The company's corporate success continued through the 1980s and early 1990s, with strong business and prospects for future growth. However, by the late 1990s, the popularity of new digital products and a decline in sales of film and processing led to increasing drops in the profits of Eastman Kodak (still the parent company to Kodak Canada Inc.). In late 1997, direct competition with Fuji Photo Film Co. and a lack of success with its new digital camera system led Eastman Kodak to announce cost-cutting measures across its corporate structure that included 10,000 job losses worldwide. ${ }^{15}$ In this corporate cutback, Kodak Canada's Weston Road headquarters, whose manufacturing activity was focused on traditional film and paper photographic products, motion picture film, and microfilm, eliminated seventy-two positions from a total of approximately 1100 employees. ${ }^{16}$

Despite these losses, production continued at Kodak Heights. In 1999, one hundred years after the establishment of Canadian Kodak Co., Ltd., the company sent a request to employees at the facility for any photographs, publications or other materials they wished to donate to a small

\footnotetext{
13 Ibid., 6.

14 Ibid., 6.

${ }^{15}$ Steven Theobald, “Kodak Plans to Slash 10,000 Jobs," The Toronto Star, November 12, 1997.

16 Steven Theobald, "Kodak Canada Cuts 93 Jobs from Payroll," The Toronto Star, December 3, 1997.
} 
company museum created for the occasion of its centenary. The resulting Kodak Canada Heritage Collection Museum, which opened on June 10, 1999, featured a selection of the donated materials and occupied one room in the Employees' Building. ${ }^{17}$ The objects not chosen for display in the museum were stored in a nearby room as an informal corporate archive and included, from the Communications Department, the thirty-three ledger books of Kodak Canada advertisements. $^{18}$

Even as Kodak Canada's centennial celebrations were underway, its parent company announced further job cuts that affected locations worldwide, including Kodak Heights. ${ }^{19}$ Despite attempts to streamline processes and refocus Eastman Kodak's mandate to serve the growing digital market, many additional jobs were lost and production and processes cut in the months and years that followed, revealing an increasingly serious corporate effort to maintain overall profitability.

In late 2004, Eastman Kodak announced plans to shut down the manufacturing facilities at Kodak Heights by the middle of the following year. The film and paper production that had taken place at the plant would return, in diminished volumes, to the Rochester headquarters, and most of the 550 positions to remain would shift to sales, marketing and customer support. ${ }^{20}$ Kodak Canada's research and development efforts would largely refocus on digital and commercial applications at its Vancouver branch, while remaining employees in the Toronto area moved from Kodak Heights to a new, smaller location.

\footnotetext{
${ }^{17}$ McDonald, 7.

${ }^{18}$ Based on the anecdotal account of Robert Burley (Assistant Professor, Ryerson University School of Image Arts, and former Director of Master's Program in Photographic Preservation and Collections Management).

${ }^{19}$ Associated Press, "Kodak Cuts 2,500 Jobs to Sustain Profit Growth,” Kitchener-Waterloo Record, July $22,1999$.

${ }^{20}$ Steve Erwin and John Valorzi, "Kodak Canada closing Toronto factory; Restructuring claims 360 jobs Photography giant 'adjusting capacity," The Toronto Star, December 10, 2004.
} 
In early 2005, the materials in the Kodak Canada Heritage Collection archive were donated to Ryerson University, with the museum objects following in a second installment soon after. In 2006, the property at Kodak Heights was sold to Metrus Properties, who began to demolish some of the structures. ${ }^{21}$ The Employees' Building remained standing, but became vulnerable through these changes. Despite its designation as a cultural heritage property by the Toronto Preservation Board, it has been left unprotected; as a result, it shows significant damage due to trespassing, vandalism and exposure to weather.

\section{Ryerson University Library Special Collections ${ }^{22}$}

When the Kodak Canada Heritage Collection was donated to Ryerson University in March 2005, a small group of students in the first year of Ryerson's Photographic Preservation and Collections Management master's program, accompanied by Robert Burley (then the program's director) and members of the library staff, made several trips to the Kodak Heights property to retrieve the material. Because there was not yet an appropriate structure within the university to care for the collection, upon its arrival the material found a temporary home in a library meeting room.

Over the following month, the students who had helped remove the collection from Kodak Heights - Siobhan Creem, Jessica McDonald, Dee Psaila and Kelly Thielen - began to process and organize the material as part of their coursework in the PPCM program. In midApril 2005, they presented an extensive written report on the collection, including sections

\footnotetext{
${ }^{21}$ Alex Bozikovic, "The End of Photography Drive: A City Landmark, and an Industry, Fade Out," The Globe and Mail, August 25, 2007.

${ }^{22}$ Unless otherwise specified, information is based on the anecdotal accounts of Robert Burley (Assistant Professor, Ryerson University School of Image Arts, and former Director of Master's Program in Photographic Preservation and Collections Management) and Susan Patrick (Ryerson University Library Special Collections Librarian).
} 
regarding the history of Kodak Canada Inc., the collection as part of Ryerson University Library, extensive documentation of the camera collection in specific, and an assessment of cataloguing options and storage and preservation concerns, along with a variety of additional resources included in appendices. $^{23}$

Through this report, it became apparent that more space and resources would be needed to adequately care for the collection than were first available. Around this time, several private collections of books and other material were donated to, or purchased by, the Library, increasing the need for a dedicated space for these valuable collections. ${ }^{24}$ The University Library made it a priority to continue developing these unique collections of material and to dedicate facilities and expertise to their management.

In January 2006, newly renovated space was designated to house the growing archive, and in December of that year, a position was created for an Archives and Special Collections Librarian. The filling of this role by former photography subject librarian Susan Patrick marked the effective creation of Special Collections as a separate entity within the Ryerson University Library system - a need that originated with the acquisition of the Kodak Canada Heritage Collection almost two years before.

In February 2007, Elizabeth Knazook was hired in a full-time contract position as a Photographic Specialist to oversee the day-to-day operations of the collections, and in Fall 2008, Special Collections was moved to a larger, dedicated space on the fourth floor of the library. Additional collections are donated to this growing body almost every year, and have thus far

${ }^{23}$ A Report: The Kodak Canada Archive and Heritage Collection at Ryerson University, by Jessica McDonald et al (Toronto: Ryerson University, April 15, 2005). This report provides an excellent history and overview of the collection at its time of entry into the Ryerson University Library system.

${ }^{24}$ These private collections included, specifically, the Nicholas M. and Marilyn A. Graver and Michael Mitchell book collections. 
included the Fred Spira and Phil Bergerson book collections, a portion of Lorne Shields's photographic collection, a "Leniniana" collection of Vladimir Ilyitch Lenin memorabilia, the MacInnis audiovisual fonds, and the archive of Canadian Architect magazine.

Amidst this rich proliferation of collections material, the Kodak Canada Heritage Collection remains a founding keystone and focal point. Detailed cataloguing and digitization (where appropriate) should make this collection accessible to a broad range of research interests, allowing the material to speak and inform new understandings of the history of photographic manufacturing and its place in Canadian culture.

\section{Kodak Canada Heritage Collection: Advertising Ledgers}

Corporate Context: Kodak Canada Inc.

By the late nineteenth century, George Eastman had already exhibited keen salesmanship with his success at bringing photography to the consumer market through flexible roll film and the inexpensive Kodak box camera. This amateur photographic revolution was aided in no small part by the positive effect of an advertising campaign employing Eastman's apt slogan, "You press the button, we do the rest."

As the quantity and readership of consumer magazines (in both the United States and Canada) grew in the early decades of the twentieth century, so did the volume of advertising done by companies hoping to reach a national audience. Eastman Kodak was no exception to this trend; a list of the largest advertisers in national magazines in the U.S. in 1915 revealed the photographic manufacturer's position as eighth, by amount of advertising, while it ranked eightieth by the size of its assets. It was the only company represented in its Standard Industrial 
Classification (SIC) category - SIC 38, Instruments and Related Products. ${ }^{25}$ As these advertising efforts grew, Canadian Kodak Co., Ltd. developed its own versions of the campaigns for the Canadian market, prepared for English and French-language publications such as Maclean's Magazine, Liberty and Le Samedi, as well as more targeted campaigns for the medical and retailer/dealer markets.

The December 1922 issue of The Kodak Salesman, a trade publication designed for Kodak dealers, contains an article explaining the particular intent and scope of that year's Christmas advertising campaign. In an article titled "Kodak and the Christmas Spirit," an unnamed author reflects on the slow start to the year's sales, and claims it necessary "that every salesman seize the opportunity of the holiday season and the final weeks of the year" to tailor their store displays and local advertising to create additional sales. ${ }^{26}$ The author goes on to suggest that holiday buyers will favor the gift "that harmonizes best with the spirit of Christmas," and that "right there Kodak has the advantage."

Slated for a circulation of a million and a half copies in various Canadian publications, ${ }^{27}$ the campaign chosen to express this communion of the Kodak brand with the holiday spirit features, as its keystone image, a cozy Christmas morning scene in which a mother photographs her daughter, the latter of whom is sitting up in bed, surrounded by her new toys. The advertisement, reproduced in The Kodak Salesman as a visual example (Fig. 1), is accompanied

\footnotetext{
${ }^{25}$ Daniel Pope, The Making of Modern Advertising (New York: Basic Books, 1983), 43-45.

26 "Kodak and the Christmas Spirit," The Kodak Salesman Vol. 8 No. 11 (December 1922): 3. ${ }^{27}$ Ibid.
} 
by additional text that describes the appealing nature of the image as the combination of "the urge to give a Kodak....reinforced by the charm of child photographs." 28

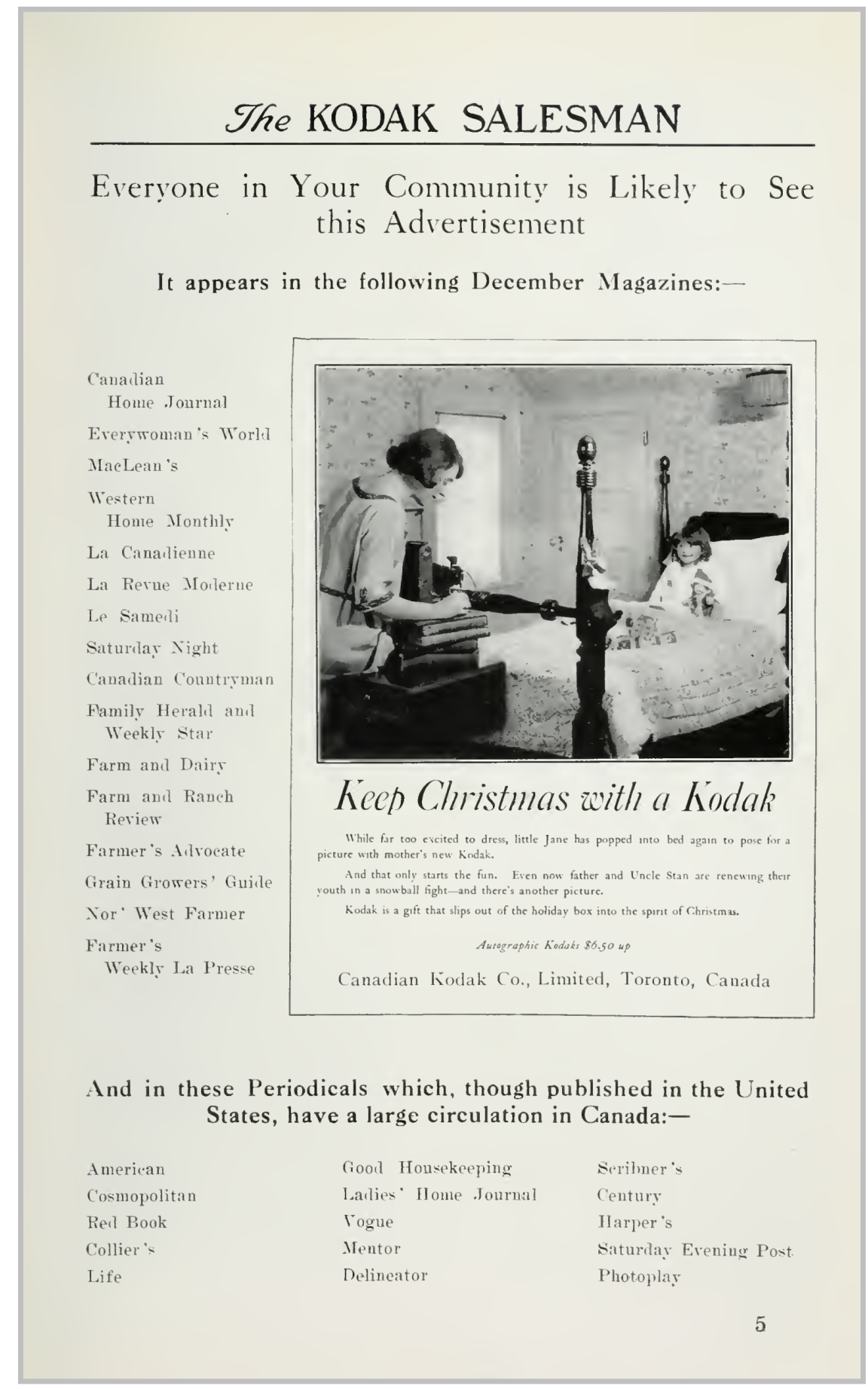

Fig. 1. Advertisement reproduced on page 5 of The Kodak Salesman, December 1922.

28 “A Big Print and a Strong Urge,” The Kodak Salesman Vol. 8 No. 11 (December 1922): 4. 
The Kodak Canada advertising collection holds a number of examples of this particular advertisement from December 1922, in several different formats favored at the time for reproduction in various publications. The full-colour version (Fig. 2) was designed for special placement in major newspapers and magazines, while the black and white rendition (Fig. 3) was likely sent to a greater number of publications; the simplified black and white line illustration (Fig. 4) - here also representing a French language version of the same campaign - could be reproduced in almost any publication. ${ }^{29}$

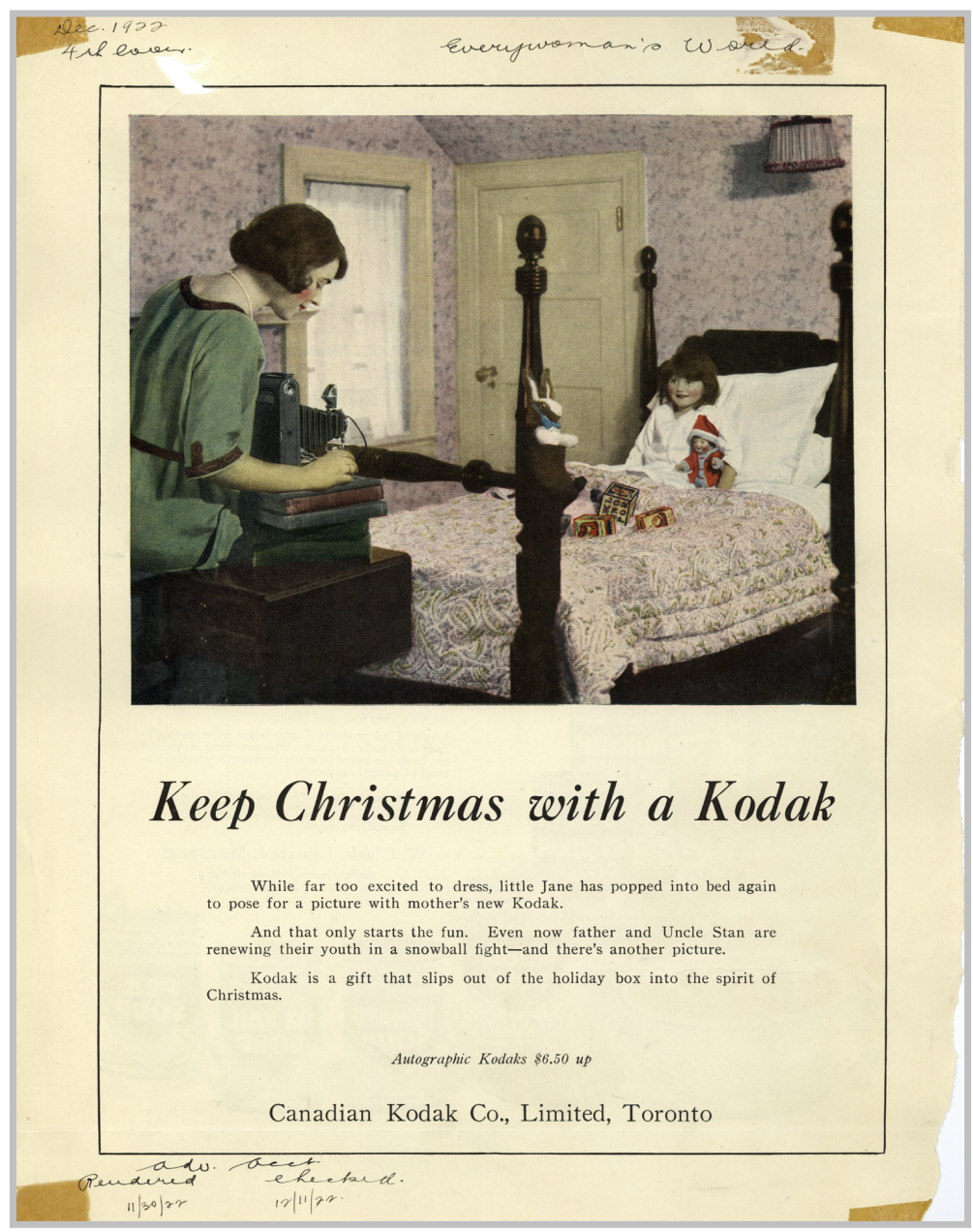

Fig. 2. 2005.001.1.1.013

Keep Christmas with a Kodak $(35.5 \times 27.5 \mathrm{~cm})$. Advertisement published in Everywoman's World, December 1922.

\footnotetext{
${ }^{29}$ These suppositions are based on information present on the advertisements themselves, and on more specific publishing information found in the article "Kodak Advertising and the Almanac," printed in the April 1922 issue of The Kodak Salesman (Vol. 8 No. 3: 3-4).
} 


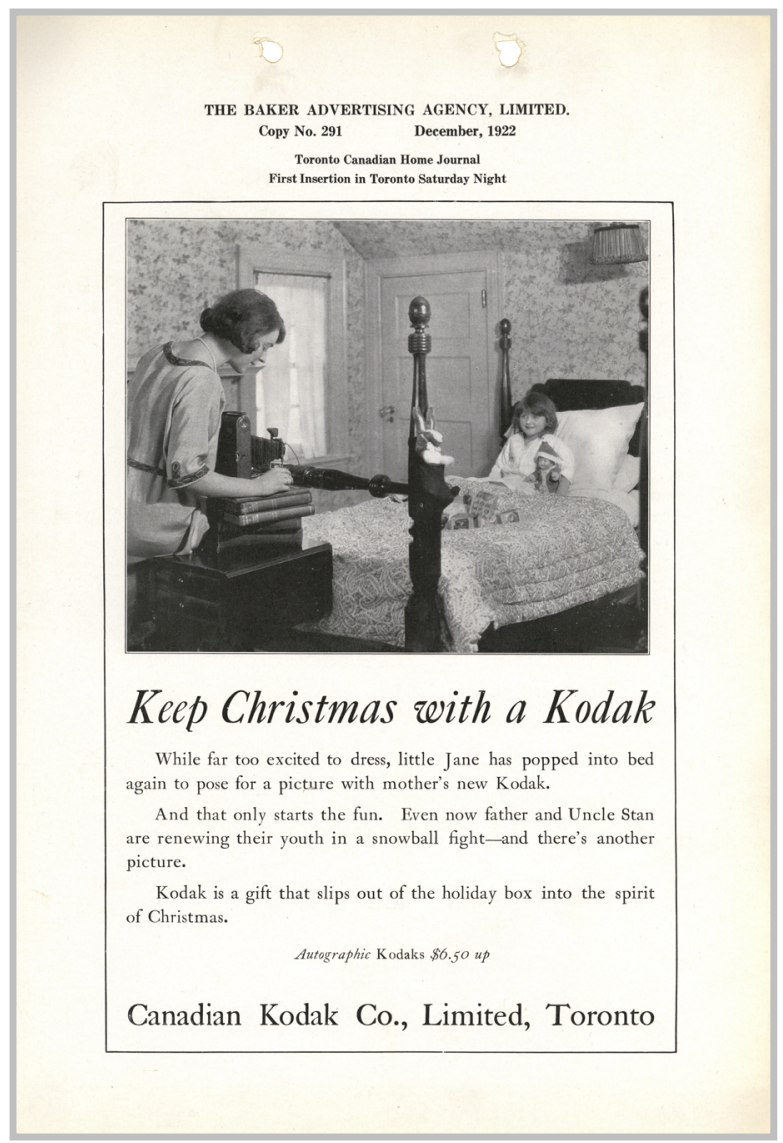

Fig. 4. 2005.001.1.1.026

Seul votre Kodak peut garder fidèlement les souvenirs de Noël et du Jour de l'an $(42.4 \times 27.8 \mathrm{~cm})$. Advertisement published in Montreal Weekly La Presse, December 1922.
Fig. 3. 2005.001.1.1.045

Keep Christmas with a Kodak $(33.6 \mathrm{x}$ $22.6 \mathrm{~cm}$ ). Advertisement published in Toronto Saturday Night and Canadian Home Journal, December 1922.

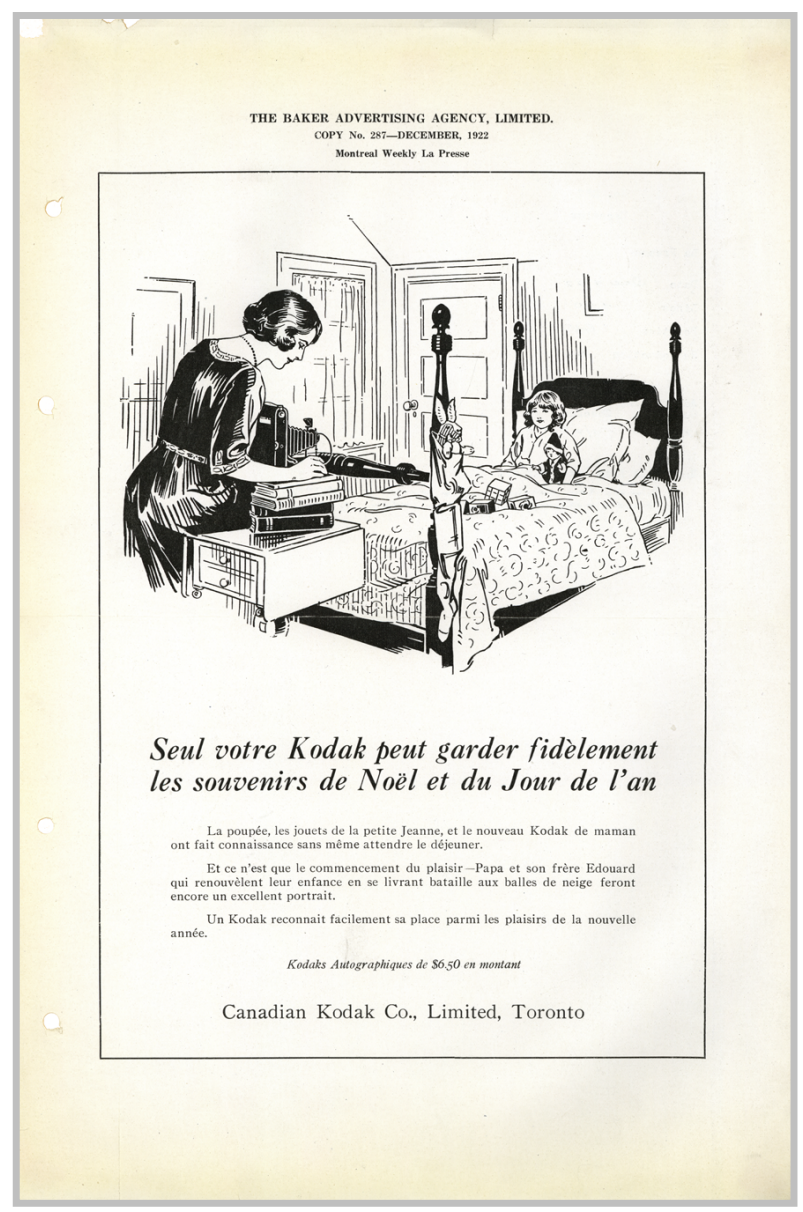


A similar connection can be drawn between contextual information available in several

Kodak Salesman issues from 1936 and the advertisements found in the ledger book for

1936-1937. Below are an example of a newsprint advertisement targeting the consumer market

(Fig. 5), an advertisement from a druggists' magazine featuring a smaller reproduction of the

same ad, along with others from that campaign (Fig. 6), and the cover of the May 1937 issue of

The Kodak Salesman, showing the same campaign reproduced - in slightly greater number - to

further inform and encourage dealers (Fig. 7).

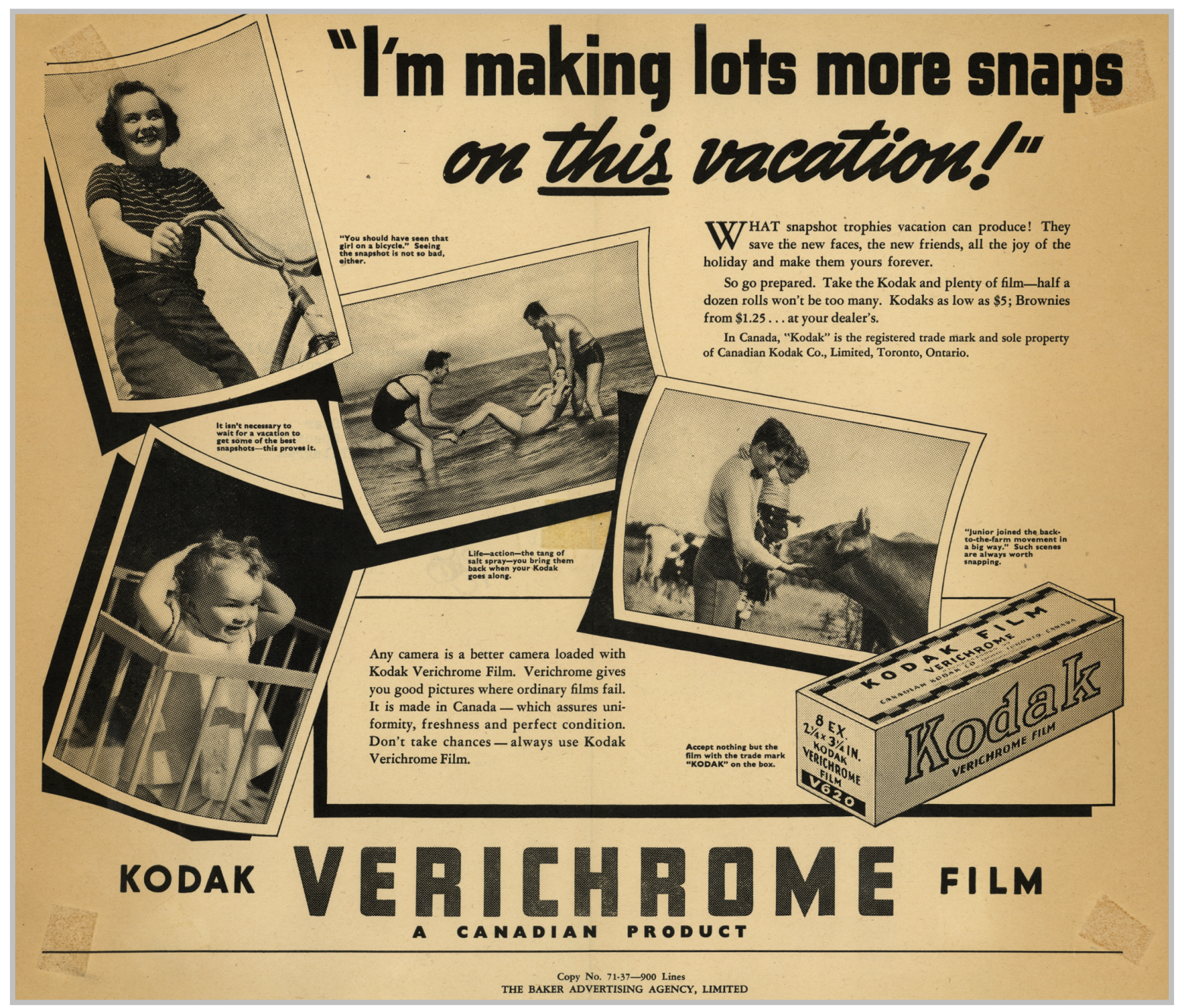

Fig. 5. 2005.001.1.7.251. “I'm making lots more snaps on this vacation!” (28.5 x $33.5 \mathrm{~cm})$. Advertisement published in Quebec Le Soleil-L'Evenement, Vancouver Province, Toronto Star, Montreal Star, Hamilton Spectator, and Toronto Telegram, June and July 1937. 


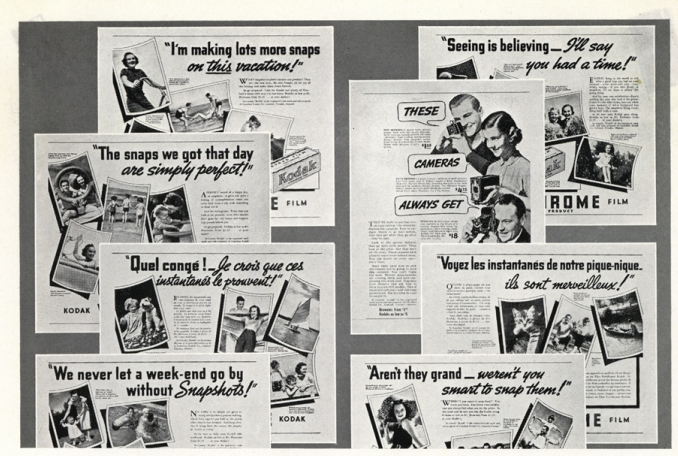

\section{Big Kodak Newspaper Campaign Now Well Under Way}

AIMED at more Kodak, Brownie, and Kodak Film sales, this biggest of all Kodak newspaper drives has already commenced in 53 leading newspapers of 39 cities. This is just one of a number of current Kodak campaigns to promote picture taking among the people and to make more camera and film and finishing sales and profits for you.

Hook up with this nation-wide advertising coverage. Feature Kodaks, Brownies and Kodak Film. Let people know that your store is the place to get these leading photographic products.

\section{CANAdian Kodak CO., Limited, Toronto, Ont.}

THE BAKER ADVERTISING AGENCY, LIMITED

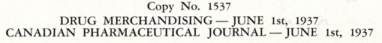

Fig. 7. Cover of The Kodak Salesman Vol. 23 No. 5 (May 1937).
Fig. 6. 2005.001.1.7.219

Big Kodak newspaper campaign now well under way $(26.1 \times 17.4 \mathrm{~cm})$.

Advertisement published in Drug Merchandising and Canadian

Pharmaceutical Journal, June 1, 1937.

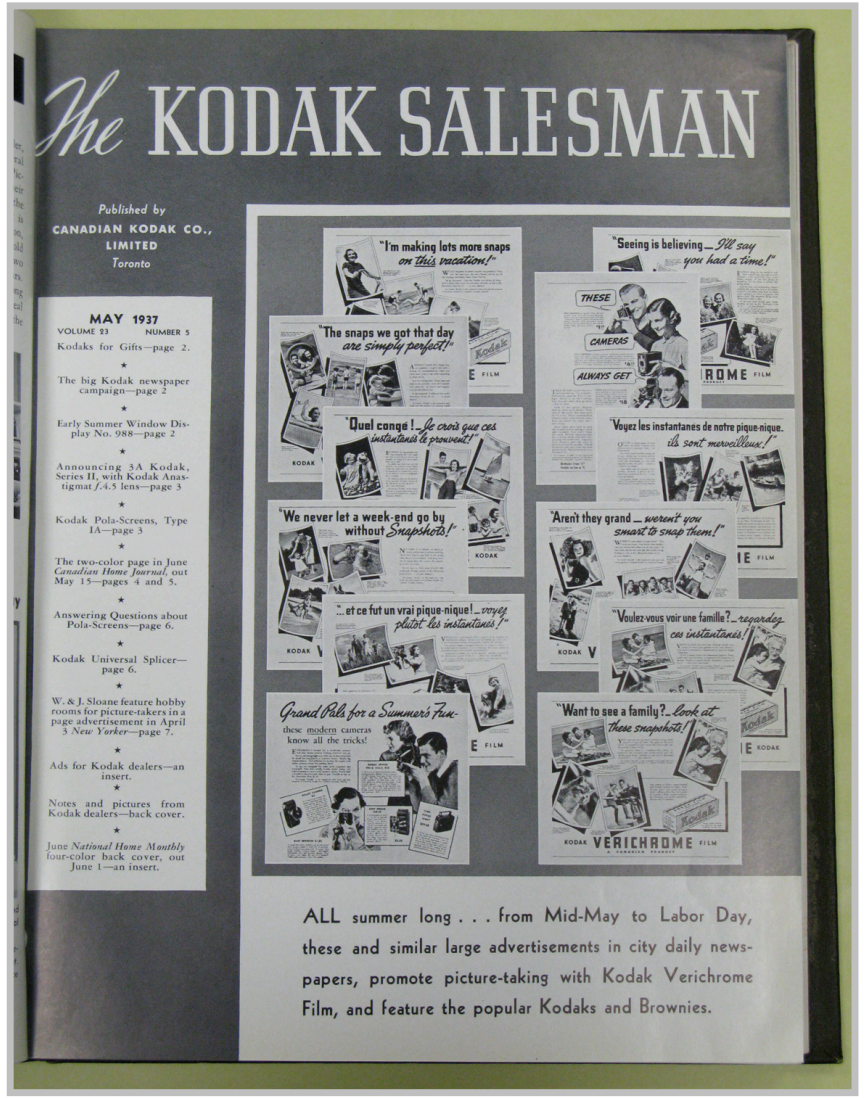


As time went on and new campaigns were released, Canadian Kodak's communications department attempted to organize and maintain a record of these advertisements - a relatively common practice for such companies. Michael Derblich, an employee of Kodak Canada's communications department from 1958 to 1995, remembers, during his early days on the job, seeing an administrative assistant inserting tear sheets or proofs of the current ad campaigns into the large ledger-sized binders in which they are found today.

While Derblich's account does not specify when this method of archiving began, his memory of the process involving current marketing materials - as opposed to a backlog of older material - suggests it began well before he joined the company's workforce. The advertisements are placed in books chronologically by year, but are disorganized at the more granular level of months and days, sometimes starting with December advertisements and jumping through other months as the pages progress. This suggests that the archiving effort may have been slightly delayed, perhaps carried out during the following year.

As his time with the advertising and communications department grew longer and the market for photographic materials became more competitive, Derblich recalls that the archiving process became more hectic and sporadic, though the collection shows that it was carried out, in some form, throughout most of his time with the company. ${ }^{30}$ The somewhat haphazard nature and attention paid to this archiving is evidenced in the treatment of the advertisements themselves - many were cropped so tightly as to cut off portions of text or printed design

\footnotetext{
${ }^{30}$ Derblich retired from Kodak Canada, Inc. in 1995. Unless stated otherwise, this information is taken from e-mail correspondence between myself and Mr. Derblich.
} 
elements. All were originally adhered to the ledger pages such that only rectos were visible, rendering inaccessible the publication and account details present on many versos. ${ }^{31}$

In addition, beginning with the 1958 ledger book and continuing through the last book at 1987, the pages are separated into market categories with roughly equal section-widths. Despite this added organization, the books remain roughly the same width as the earlier books, whose contents most heavily represented the consumer market. A cursory look at the "Consumer" section of the 1960 ledger book contains advertisements from December backwards only to June, which even more strongly evinces the incomplete nature of this archiving.

These factors suggest that the Communication Department's intent in preserving these advertisements was not, at least in practical terms, to maintain them in pristine condition as an absolutely comprehensive archive; rather, it appears to have been an effort to routinely contribute to a visual archive of the ads as a fairly standard method of corporate record-keeping - one that was not given a great deal of attention or priority as time went on. I have not found evidence to suggest that the archive was actively accessed or referenced by the Communications Department, apart from its use in preparation for the 1999 Kodak Canada Inc. centennial celebration and its placement in the Kodak Canada Heritage Collection.

\section{Current Context: Ryerson University Library Special Collections}

\section{Now part of the Kodak Canada Heritage Collection in Ryerson University Library's}

Special Collections, the ledger books - thirty-three in all - each contain advertisements from one, two or three year periods: the earliest book's contents range from 1922 to 1923, and the last book

\footnotetext{
31 This inscribed information has become accessible in recent years due to the degradation of the adhesive on the clear tape used to attach the advertisements to the ledger pages; it has become dry and brittle, releasing the prints from their pages and lending access to the backs of many of the advertisements.
} 
ends with advertisements from 1987. The size of the collection, paired with the necessarily limited scope of this project, made it possible for me to process only two of the thirty-three ledger books. The chosen volumes, covering the years 1922 to 1923 and 1936 to 1937, contain 217 and 267 advertisements, respectively, for a total of 484 individual items catalogued and digitized. Figs. 8-11, below, show the advertising collection's physical context in Special Collections.

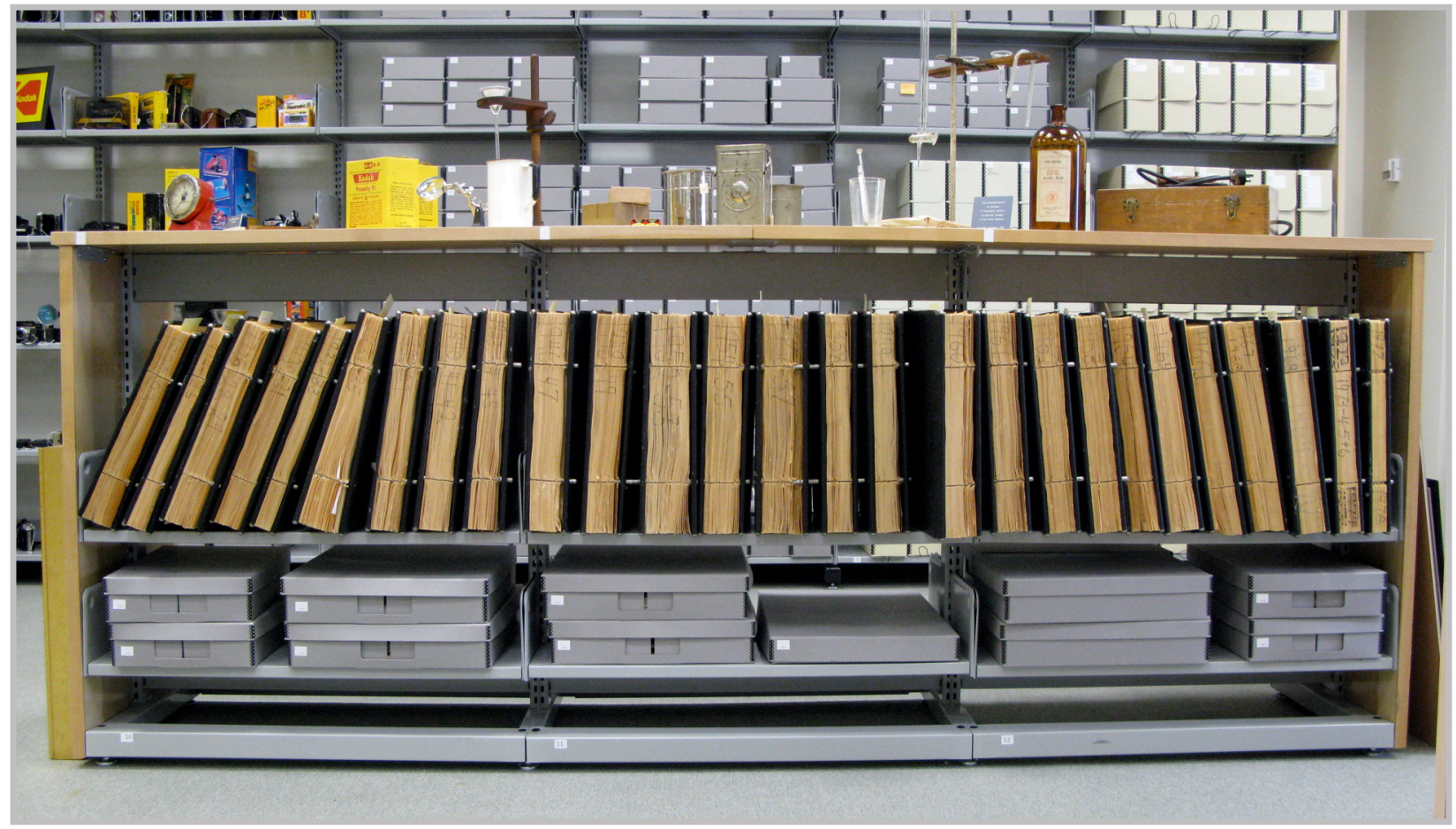

Fig. 8. Twenty-seven of the thirty-three advertising ledger books, housed in a shelving unit with other Kodak Canada Collection material in Ryerson University Library Special Collections. 


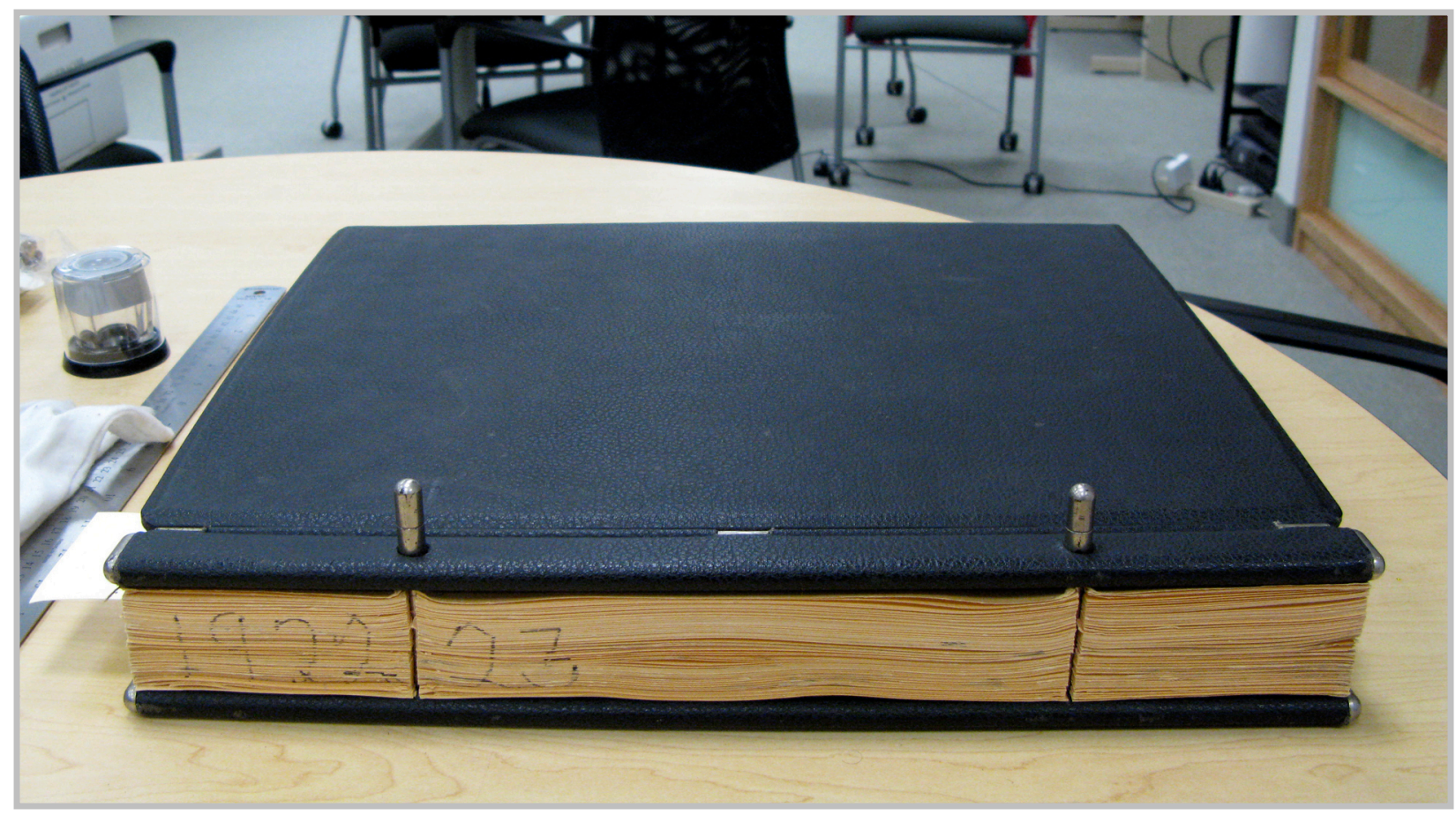

Fig. 9. 2005.001.1.1. Kodak Canada Ad Ledger, 1922-1923 (44.4 x 37.8 x 8 cm). Ledger book of 217 advertisements from 1922-1923, preserved by Kodak Canada Inc. and now held in Ryerson University Library Special Collections.

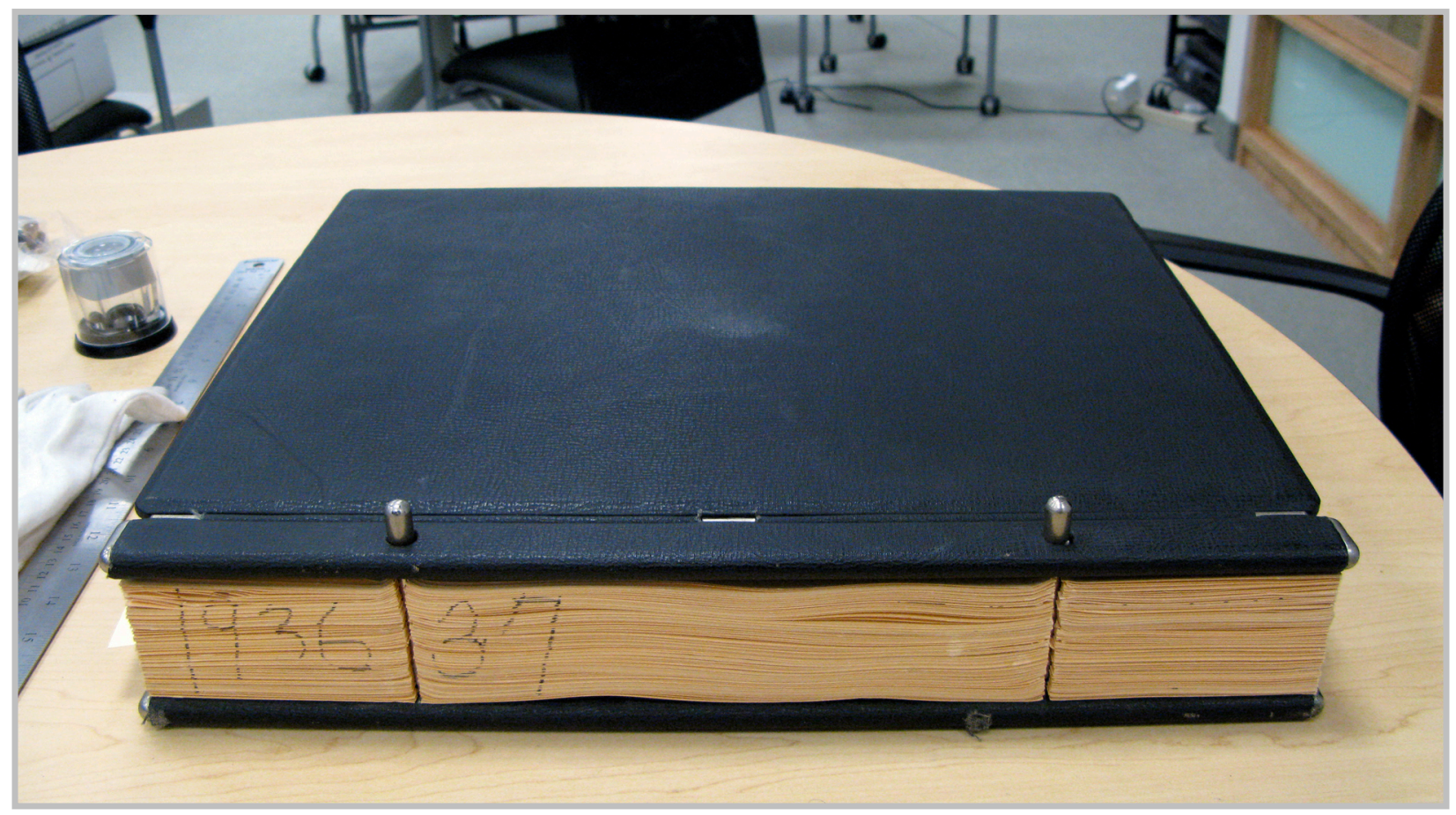

Fig. 10. 2005.001.1.7. Kodak Canada Ad Ledger, 1936-1937 (44.4 x 37.8 x $8.3 \mathrm{~cm})$. Ledger book of 267 advertisements from 1936-1937, preserved by Kodak Canada Inc. and now held in Ryerson University Library Special Collections. 


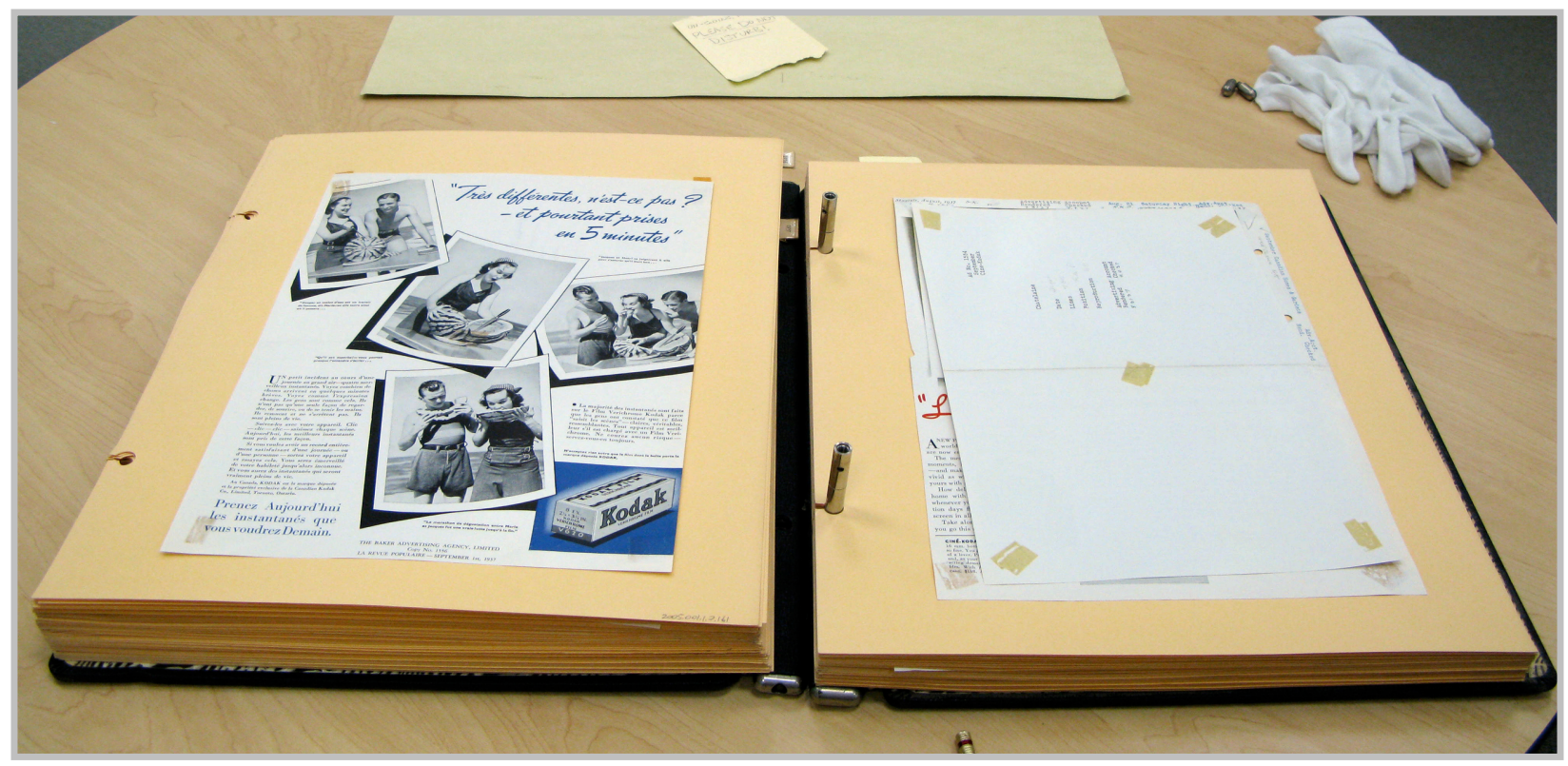

Fig. 11. View of pages from Kodak Canada Ad Ledger, 1936-1937, showing ads from 1937. The photograph was taken during the digitization process, when the book was partially dismantled.

While the number of advertisements seems to decrease in more recent ledger books (likely corresponding to the increasingly sporadic archiving on the part of Kodak Canada's Communications Department recalled by Derblich), a conservative estimate of similar numbers for the first ten books alone - representing the years 1922-1945 - presents a partial total of more than 2000 individual advertisements. This suggests that a count of the complete advertising collection could easily surpass 4000 individual advertisements, though the lower page total and existence of blank pages in later volumes adds to the difficulty of estimating this with much accuracy.

\section{Significance}

The advertisements contained in the ledger books present an unmistakably significant resource for research in a variety of disciplines. The collection is particularly valuable for the 
contained, corporate record it presents of the development and transformation of the consumer photography market in Canada. In combination with other materials in the collection, such as volumes of The Kodak Salesman, it forms a unique resource regarding the development and marketing of vernacular and amateur photography throughout the twentieth century.

The visual and textual content of each advertisement also creates an unmistakable reflection of its particular historical and social context. From the colloquial phrases used in headlines, to the changing styles of dress, to the portrayal of men and women in their understood gender roles, to the more patriotic tone included in times of war, the advertisements map a course through changing societal norms and values, significant in no small part for what - and whom - is excluded. These material artifacts trace a changing consumer consciousness, and as such, could be of significant intellectual interest to scholars of material and visual culture and gender and women's studies, in addition to historians of marketing and advertising in North America.

At a fundamental level, the collection also provides a tool for understanding, through changes in branding, marketing schemes and product offerings, a significant Canadian company's development and evolution over years of dynamic change in its profitability and market share. A great deal can be learned and deduced about the operations and philosophy of the company, even as these directly affected its customers. In all, the advertising collection and other corporate material in the Kodak Canada Heritage Collection present significant opportunities for new research and analysis in a number of fields - research that I hope will be encouraged through the organization and digitization of this material. 


\section{Chapter 3: Cataloguing}

\section{Goals}

To fulfill the project's goal of increasing accessibility to the advertising collection, the records - paired with a digital surrogate image of each advertisement - must contain the data necessary to lend a variety of points of access to the objects in a searchable electronic system. Further, as the advertising ledgers, themselves, make up only a small part of the larger Kodak Canada Heritage Collection, the connection between the advertisements in the collection and other material in the archive, and with the archive itself, should be maintained and supported through the catalogue records created during this project.

As such, the cataloguing must be well-organized and consistent, and follow standards that allow the data to be transported and transformed into other settings and formats. More specifically, these new records must conform to the standards already adopted by Special Collections for the cataloguing of this type of archival material, to ensure compatibility with existing catalogue records and to facilitate data migration into a collections management system slated for introduction later this year. ${ }^{32}$

As mentioned previously in the Introduction and Chapter 2, the scale of the advertising collection made impossible the processing of all thirty-three ledger books during this project. My selection of two books provided a manageable amount of work to complete during the time alloted. Therefore, to facilitate expansion of the work into the remaining ledger books, the cataloguing methodology must also be well-documented and scalable to a larger quantity of material.

\footnotetext{
32 The new Minisis collections management system (CMS) will be shared with Ryerson University Library Archives, with each organization adding collections material in its own area. The website collections portal intended to accompany the new CMS will be also be shared cooperatively between the two bodies.
} 


\section{Cataloguing Practice and Format}

The ledger books for 1922-1923 and 1936-1937 contained 217 and 267 advertisements, respectively, for a total of 484 objects to be catalogued and processed. Because Special Collections has not had, up to this point, a database-driven collections management system, catalogue records have been created in electronic spreadsheets.

Some of the books and audio-visual material in Special Collections have been described using the Anglo-American Cataloging Rules (AACR2R) content standard to facilitate their addition to the existing Ryerson University Library catalogue. However, the Canadian Council of Archives' Rules for Archival Description (RAD) has been selected as the most appropriate content standard for the cataloguing of other archival material in Special Collections, and in particular, the material in the Kodak Canada Heritage Collection. ${ }^{33}$ Guidelines for the application of this schema to Special Collections material have been set forth in an internal document titled Guide to Cataloguing Special Collections at the Item Level.

The advertising collection had been previously catalogued at book-level using RAD. ${ }^{34}$ Through planning discussions with Elizabeth Knazook (Photographic Specialist, Special Collections) and Trina Grover (Head of Cataloguing, Ryerson University Library), I structured my own cataloguing spreadsheets around these pre-existing records, and added several additional

\footnotetext{
33 The RAD standard was first published by the Bureau of Canadian Archivists in 1990, and has, since then, been widely adopted across the Canadian archival community. A revision to the standard was published in 2008 by the Canadian Committee on Archival Description - a body tasked by the Canadian Council of Archives (CCA) with the maintenance and continuing development of the standard. The CCA continues to promote and support RAD as a key standard for Canadian archival institutions.

More information regarding RAD can be found in Canadian Archival Standard: Rules for Archival Description, the RAD guide published in 1990 (and revised in 2008) by the Bureau of Canadian Archivists. It is available to download as a PDF file from the CCA's website at http://www.cdncouncilarchives.ca/archdesrules.html.

${ }^{34}$ The RAD accession number structure applied to these ledger books - already extended for the Kodak Canada Collection to denote material type - placed the book records at item level.
} 
fields to facilitate the descriptive specificity needed for the individual advertisements. For these new fields, I adhered to the RAD descriptive structure where possible, but also incorporated controlled vocabularies and authority files such as the Library of Congress's Thesaurus for Graphic Materials (TGM).

Below is a basic list of the standards/schema used, with a brief summary of the fields used from each. These resources are available online, and have been consulted through that medium during the cataloguing process.

\section{$\underline{\text { Rules for Archival Description }}^{35}$}

Used to denote accession number and location, date, titles and statements of responsibility, physical descriptions, inscriptions, access points and notes pertaining to the preceding fields.

\section{Library of Congress: Thesaurus for Graphic Materials (TGM) ${ }^{36}$}

Referenced to supply appropriate terms for medium (TGM II: Genre and Physical Characteristic Terms) and the subjects/content of the advertisements (TGM I: Subject Terms).

\section{$\underline{\text { Kodak Products }}$}

Refers to an additional field created to textually record the products being advertised. Camera names are based off of a comprehensive list of Kodak cameras available as Kodak Tech Pub AA-13 ("History of KODAK Cameras"). ${ }^{37}$ Other products, such as film, are recorded by name in a consistent format; in the future, these entries could contribute to the creation of a product-based authority list.

\footnotetext{
${ }^{35}$ Available for download as PDF files on the Canadian Council of Archives website, currently found at http:// www.cdncouncilarchives.ca/archdesrules.html.

${ }^{36}$ The Thesaurus for Graphic Materials is available on the Library of Congress website. TGM I is currently described at http://www.loc.gov/rr/print/tgm1/. TGM II is described at http://www.loc.gov/rr/print/tgm2/. Both parts of the resource can currently be searched or browsed from the page http://lcweb2.loc.gov/pp/tgmiquery.html.

${ }^{37}$ Kodak Tech Pub AA-13 can currently be accessed online at http://www.kodak.com/global/en/consumer/products/ techInfo/aa13/aa13.shtml.
} 
A more comprehensive table listing each field with its source schema and definition/use is included in Appendix A (page 46), and examples from a cataloguing spreadsheet are provided in Appendix B (pages 47-48).

Working within scheduling constraints and limited hours of access to equipment, I completed both the cataloguing and digitization of the 484 advertisements on a very part-time basis over the course of approximately five months, including the time needed to rescan certain advertisements. ${ }^{38}$ I would estimate, however, that a full-time archivist, able to focus the majority of his or her attention on the collection, and given access to dedicated and well-functioning equipment, could likely complete these steps with a similar number of advertisements in several months' time - perhaps taking only three to four weeks for the cataloguing and digitization of material from one ledger book. This time would, of course, vary depending on the size and content of each ledger book, and on the particular working methods of the individual cataloguer. For instance, the time needed may decrease when addressing the books of advertisements from the 1980s, which seem to contain fewer pages and advertisements.

\section{Issues and Considerations}

\section{$\underline{\text { Accession Numbers }}$}

At the outset of the cataloguing process, a decision was needed regarding the structure of the new accession number for each advertisement. The ledger books had already been given item-level numbers using the RAD format, with the insertion of an additional number segment

\footnotetext{
${ }^{38}$ The decision to rescan certain items is described below, on pages 35-36, in "Chapter 3: Digitization: Digitization Practices and Standards."
} 
given to all Kodak Canada Heritage Collection material to denote its general material type; this left no further room for expansion within the RAD guidelines. ${ }^{39}$

Though the numbering system was already somewhat cumbersome, I believed it was important to extend the same basic format used for each ledger book to each of its constituent advertisements; in this way, the relationship between the individual objects and the books in which they were found would remain unbroken. I felt that using a new denotation - one that would need to be tracked and understood separately from the already-established pattern - would add unnecessary complexity to this otherwise straightforward relationship.

The decision to extend the existing format resulted in longer, more complicated accession numbers. However, the structure still follows a logical pattern, and one that could be extended to other material in Special Collections in which an object already catalogued at item level contains multiple more specific items.

\section{Consistency of Language and Terminology}

Despite one's best attempts to control terminology and format, cataloguing remains, in part, a subjective process. Maintaining consistency in language can become a struggle, especially when faced with cataloguing multiple objects with similar content.

While fields populated with terms from vocabularies and authorities - if well-monitored can be kept relatively consistent, as can those with pre-defined formats (such as dates and object dimensions), "free entry" fields such as those used for descriptions and notes render absolute consistency almost impossible. Though these descriptions can greatly improve keyword access to the objects and records, word tense, format and style can become extremely varied, even

\footnotetext{
${ }^{39}$ The progression of this numbering format from the book-level to print-level records can be seen in the sample catalogue spreadsheet page included in Appendix B on page 47.
} 
between records added by the same cataloguer. This inconsistency, in turn, can hinder a researcher's success at retrieving relevant and accurate search results.

To address this issue, I decided to employ the most concrete and basic terms as I could to describe, in free text descriptions, the content of an advertisement. For example, instead of describing an advertisement that depicted a man, woman and young child using terms such as "mother," "father," "family" or "toddler," I would use simply "woman," "man" and "child." Similarly, "adults" and "children" could be used in place of individually denoting each character pictured.

In this way, I hoped to provide enough information to facilitate fairly detailed searches through an electronic interface; the terms used above, if used consistently, can be visible keywords in the search process that enable a researcher to tailor his or her query to a great degree of detail without turning to subjective or projected cultural ideas regarding family or other relationships. The more abstract concepts, where clearly suggested in the context of an advertisement, are instead recorded in the appropriate subject fields, using specific terminology taken from the authorities discussed above. As such, free text fields can retain a certain level of objectivity, while more specific contextual (subject) terms can still be used for narrowing a user's search results.

\section{Transcription versus Summarization}

The last issue I will address in this section is that of transcription versus summarization. Because the time and effort needed to transcribe the entire text of an advertisement were not sustainable, I was quickly faced with the need to set decisive limits that I would feel comfortable working within for the whole of the cataloguing project. 
I sought out other collections of advertising material, seeking especially those available online, to gauge the amounts of literal transcription and levels of access reflected in those records. ${ }^{40}$ Based on these observations, as well as my working conception of the audience for this advertising collection, I decided to transcribe only the main headline or slogan of each advertisement to serve as its Title. When an advertisement used more than one of Kodak's repeated catch-phrases as a major line of text, I record both in this field, adhering to the RAD format for "Formal Title." In this way, a user could search for phrases such as "This snapshot fixed everything," and "The snapshots you'll want tomorrow -- you must take today," which are sometimes found in the same advertisement, and retrieve appropriate search results in either case. The consistent transcription of these slogans could enable a user to search for and retrieve all recorded examples from a particular advertising campaign, or study the evolution of a particular slogan throughout its lifespan in the advertising collection.

The "body" text of an advertisement, then, is described through a very general summary in the Description field. It is my hope that a user who needs to access more completely the text of a particular advertisement or marketing campaign will be able to access appropriate records using the tailored searches mentioned above, and can gain the additional information needed through the digital images provided. While it is impossible to predict with certainty the future use of this collection, I expect that the cataloguing decisions made, and the resulting metadata, will provide comprehensive descriptions and facilitate effective searching and use of this valuable resource.

\footnotetext{
${ }^{40}$ These included the Ellis Collection of Kodakiana held by the Duke University Libraries in Durham, North Carolina - currently accessible online at http://library.duke.edu/digitalcollections/eaa/browse/kodak/ - and the Kodak Advertising Collection, which is part of the Eastman Legacy Collection at George Eastman House in Rochester, New York.
} 


\section{Chapter 4: Digitization}

\section{Goals}

Each advertisement's digitized image will serve as the researcher's primary visual reference for the object. These digital surrogates should also protect the original objects by decreasing their need to be handled. Additionally, the creation of a web-based interface will allow interested persons, be they members of the Ryerson community or elsewhere in the world, to view the collection and gather information online. For these reasons, it is key that the images accurately reflect the advertisements themselves and retain as much visual information from the original objects as possible.

The advertisements have not, to this point, been preserved as pristine, perfect examples of printed advertisements; their irregular dimensions and sometimes too-tight cropping - in combination with damage caused by the tape adhesive used long ago to attach them to the ledger pages - suggest that these objects were retained by Kodak Canada's Communications Department as a somewhat informal record of the company's advertising activity, rather than a carefully protected and categorized collection of fine objects.

For these reasons, I believe that the content of the advertisements, both literal and abstract, is of the greatest overall value in this collection, rather than the more minute details regarding printing techniques, ink-fading or states of preservation. While the accurate reproduction of colours and tonal values is an important benchmark, I believe that, to most fully serve their intended purpose, the digital surrogates must - at minimum - retain the legibility of all text, images, and layout/design devices retained on the original object. 


\section{Digitization Practices and Standards}

I began the digitization process using the scanner already in place in Special Collections. Before I began to scan the objects, I researched digital image capture and image file standards and guidelines from several other institutions, including the Smithsonian Institution Archives, the California Digital Library, and the U.S. National Archives and Records Administration (NARA) ${ }^{41}$ I then compared their recommendations to the capabilities and limitations of the equipment and software available on the scanner and computer designated for my use in Special Collections. Due to the limited nature of these options, as well as the irregular dimensions of many of the advertisements, I was unable to follow precisely all recommendations presented by the institutions mentioned above; however, I reached what I believe to be an adequate compromise for creating digital surrogates of the required quality.

The advertisements from 1923 in the first ledger book, and from 1936 and the first half of 1937 in the second ledger book, were scanned using this initial equipment and setup. Due to the small size of the machine's scanning bed, two scans were needed to create recto composites for many of the advertisements, requiring more intensive post-capture image stitching and editing in Adobe Photoshop. I was displeased with the inconsistency and loss of authenticity that I felt resulted from the editing of these digital surrogates, and inquired whether a larger scanner could be made available - one more suited to the digitization needs not only of my project, but of Special Collections as a whole.

\footnotetext{
${ }^{41}$ The Smithsonian Institution Archives's digitization standards can currently be found online at http:// siarchives.si.edu/records/records_erecords_digitization_images.html. The California Digital Library's guidelines can be found online - or downloaded as a PDF file - from http:/www.cdlib.org/inside/diglib/guidelines/bpgimages/. NARA's digitization guidelines can be downloaded as a PDF from http://www.archives.gov/preservation/technical/ guidelines.pdf.
} 
When the project entered its second phase at the beginning of May 2009, a larger, faster scanner was made available for my use in the Circulation area of Ryerson University Library. This new setup gave me a greater ability to adjust scan settings, and provided a scanning bed large enough that many of the advertisements requiring two scans using the original system now required only one - and therefore, much more limited image editing. As the integrity of the digital surrogates was of great importance, I chose to dedicate the time necessary to re-scan each advertisement from 1923 and 1936-37 that had initially required two recto captures. The basic equipment, software and file specifications for both the initial and secondary setups are presented in comparison with NARA recommendations in the table in Appendix C (page 49).

The digital surrogates of each advertisement have been presented to Special Collections in four resolutions or sizes: one digital master image at the scanned size and resolution (600 pixels per inch, or ppi), to be kept as the base image from which the others are derived; one image at the scanned size but reduced to $300 \mathrm{ppi}$, from which actual-size printed reproductions can be made; one "access file" representing the image at a reduced size and resolution - $72 \mathrm{ppi}$ and 800 pixels along the longest dimension - for web display; and one "thumbnail" version at a resolution of $72 \mathrm{ppi}$ and 150 pixels on the longest dimension, for use in browsing the collection and displaying search results online. "Table 2: Digital Master and Derivative Image Specifications," found in Appendix C on page 50, contains example images, corresponding file sizes, and other specifications, including the file-size totals for all 484 images captured in each format, and a comparison to NARA recommendations. ${ }^{42}$

\footnotetext{
${ }^{42}$ Note, however, that only the "thumbnail" image in that table is reproduced at actual size. The other images were reduced to fit into a single-page table format.
} 


\section{Issues and Considerations}

\section{Limited Resources and Consistency}

There were a number of issues to consider and choices to be made during the digitization phase of this project. Resource and time constraints dictated that this project was, at first, undertaken using equipment and technologies that were not state-of-the-art, as is sometimes the case for projects of this nature. The situation was not ideal, but it provided me with the opportunity to assess the options and arrive at what I found to be the best available working method for capturing the material, given the allotted time and resources. When better resources became available, I was able to reassess my options for completion of the project, and to arrive at a compromise that I feel adds integrity to the pairings of metadata and digital surrogates that comprise the final product of this work.

As mentioned above in "Chapter 3: Cataloguing: Cataloguing Practice and Format," I completed both the cataloguing and digitization of 484 advertisements on a part-time basis over an extended period of time. I would expect an individual, able to dedicate the majority of his or

her time to this material, and with extensive access to well-functioning equipment, to complete this volume of work in a much shorter time.

\section{$\underline{\text { Irregular Dimensions and Completeness of Information }}$}

Many of the advertisements in the ledger books were cropped or otherwise trimmed at some point after their creation; very few have regular, rectangular dimensions, and in many cases, especially where smaller advertisements are concerned, the verso inscriptions remain only in part, resulting in incomplete text. The irregular dimensions also presented me with a decision 
to make regarding the extent of the image editing to be done. Was it important to keep the rough, torn or uneven edges of the advertisements visible in the digital surrogate?

Because I believe, for these purposes, that the content of the advertisements is the most important aspect to capture, in cases where advertisements were simply cut unevenly, I chose to crop each digital surrogate to the largest rectangle possible, given the advertisement's dimensions. However, where such cropping would have resulted in a loss of information, I left uneven edges visible. Where an advertisement had a rough edge or other physical factor that seemed to express something of its character or experience as an object - such as the fragile, torn edges of many of the newspaper clippings - I attempted to preserve as much of this edge as I could, while still cropping somewhat for a "clean," regular image.

\section{File Storage and Back-ups}

The creation of digital master images at the high resolutions and bit-depths specified above resulted in a wide range of file sizes, from about 20-130 megabytes in size. This presented an immediate need to establish a reliable - and sizable - storage environment, as well as some "permanent" format in which to archive back-up copies of the image files.

During project planning meetings with Special Collections and Library staff, I requested access to a library server, one from which data back-ups were made. Unfortunately, the strict access limits applied to Ryerson student accounts made it impossible for me to save my work directly to such a server. As an alternative, I chose to invest in two portable storage devices - one a portable hard drive sizable enough to comfortably store all scanned images and other data, and the other a 16 gigabyte USB "memory stick" that would act as temporary storage and allow me to transport some, but not all, of the images between the various computers and the portable 
drive. In this way, the USB stick became my day-to-day device, allowing me to preserve the portable hard drive in a safe place as my master data bank. In addition, I regularly created DVD back-ups of the image files; these discs archive the data on the portable hard drive, and as of yet have not been used for file retrieval.

The large master files, printable images, website-ready access images and smaller thumbnail image files will all be transferred to machines in Special Collections - and, ideally, backed-up library servers - using additional DVDs that can then be kept in the collection as backup copies. The entire collection of images, including all four formats/sizes and representing the material from both ledger books - requires approximately 75 gigabytes of available storage. ${ }^{43}$

\section{Copyright Ownership and Restrictions}

While the Kodak Canada Heritage Collection has rested amongst Ryerson University's archival collections for some years, there has not yet been a formal copyright or use agreement put into place between Kodak Canada Inc., and Special Collections. As the ownership of copyright, where applicable, still resides with Kodak Canada Inc., allowable uses of the material should be determined carefully on a case-by-case basis.

While this condition of ownership could prove to be problematic - or at least an issue to resolve - where the online publishing of the digital images of advertisements is concerned, the creation and maintenance of the digital surrogate images, themselves, seems to be allowed for in Section 30.1(1)(a)(i-ii) and (d) of the Canadian Copyright Act. This portion of that lengthy and complex document states that:

\footnotetext{
${ }^{43}$ File specifications and size information can be found in Table 2 in Appendix C (page 50).
} 
It is not an infringement of copyright for a library, archive or museum or a person acting under the authority of a library, archive or museum to make, for the maintenance or management of its permanent collection or the permanent collection of another library, archive or museum, a copy of a work or other subject-matter, whether published or unpublished, in its permanent collection

(a) if the original is rare or unpublished and is

(i) deteriorating, damaged or lost, or

(ii) at risk of deterioration or becoming damaged or lost...[or]

(d) for the purposes of internal record-keeping and cataloguing. ${ }^{44}$

This provision seems to adequately cover the digital surrogate images created during my project. Certain other uses or reproductions, including copies made for researchers or patrons for strictly noncommercial purposes of private study, may fall under the copyright exception of "fair dealing." However, the complexity of copyright law - and the consequences of violating it, whether knowingly or unknowingly - are too high to set out any comprehensive use guidelines without acquiring legal advice. Ideally, to ensure that future or other uses do not violate copyright, a written usage agreement should be reached between Special Collections and Kodak Canada Inc., establishing some basic parameters and permissions.

\footnotetext{
${ }^{44}$ Copyright Act ( R.S., 1985, c. C-42) is available online, in the "Justice Laws" section of the website of the
} Department of Justice Canada, at http://laws.justice.gc.ca/en/showtdm/cs/C-42. 


\section{Chapter 5: Website Planning}

\section{Goals}

The basic goals of most websites are to, in some way, inform, educate, and/or persuade. ${ }^{45}$ In the case of a collection or archive's website - such as the upcoming, redesigned site for Ryerson University Archives and Special Collections - the most prominent of these goals may be to inform and to educate. Whatever the primary goal, a site should be designed for ease of use, keeping the needs and interests of the most likely users in mind from the earliest planning stages through the final phases of design tweaks and visual modifications.

My specific goal in presenting the Kodak Canada advertising material online is to create an avenue of remote access to the material for researchers. This should, then, enable the collection to be studied at a variety of levels, from a brief, recreational, human-interest "browse" to a more in-depth comparison or analysis that could contribute to an academic or intellectual project. In more practical terms, the site's initial presentation of information should inform a user about what collections are held within these university departments, and further, what types of material each component collection contains. The user may then choose to dig deeper into the online content, looking at specific material by browsing available collections or searching for specific objects, perhaps spurring an educational process that could lead to further investigation or research.

The recommendations put forth below and in Appendix E were refined through discussions with the staff of both archival departments; they are practical and appropriate to the circumstances, and should improve the online presence and visibility of the Archives and Special

\footnotetext{
${ }^{45}$ Christina Wodtke and Austin Govella, Information Architecture: Blueprints for the Web (Berkeley, CA: New Riders, 2009), 37.
} 
Collections. These recommendations include an architectural mapping of the entry and informational pages hosted on Ryerson University Library's main website, as well as diagrams of pages hosted within the separate website portal that will run in connection with their shared collections management system and database. As initial suggestions, these have already helped establish a starting point for the internal discussions and planning meetings that will take this website further toward completion.

\section{Key Features}

To help meet the goals set forth above, it would be ideal for the "front" page of the University Archives and Special Collections site to include a search box, providing an option to search available records by collection and/or keyword. If this is not practical, the collections should be searchable from one step further in, on a page specific to either Archives or Special Collections. At a basic level, the Kodak Canada advertising collection - or any other collection made available through the shared site - should be quick and easy for a user to locate, with a minimum of intervening steps or "clicks."

The collection-specific page should feature a collection-level archival description and, perhaps, several sample images. This page should offer both basic and advanced search options, allowing the user to pursue the material at his or her own level of interest without having to click through intervening pages.

The advanced search should provide the option to search by title, date, publication information, product, and subject. Additionally, the display of search results could include a list of various categories represented by the gathered records, revealing the breadth of content 
present and providing a tool for further refining the search. ${ }^{46}$ The user could then select a search result (i.e. an object record), and be taken to a page displaying the object's record, along with a thumbnail image.

This record display could either be partial, with the option to click a link to see the full textual record, or could immediately include all relevant fields. The thumbnail image should be clickable, resulting in the display of the larger access image, either in a separate (popup) window or through an internal popup function such as Lightbox2 - a free Javascript tool created by Lokesh Dhakar. ${ }^{47}$ Further browse and search features could be included on the object page, given the availability of additional programming resources. Diagrams for suggested site architecture and basic page structures are included in Appendix E (pages 57-59).

\section{Copyright and Restrictions of Use}

For a general discussion of copyright concerns regarding the advertising collection, see pages 37-38, above (in “Chapter 4: Digitization: Issues and Considerations: Copyright

Ownership and Restrictions"). I believe that the inclusion of low-resolution digital images from the Kodak Canada advertising collection as part of the record display in a web-based catalogue

\footnotetext{
${ }^{46}$ A good example of this can be seen in the search interface to the online advertising collections at Duke University Libraries. The options to narrow a search are on the left of the screen when browsing the "Ellis Collection of Kodakiana (1886-1923)" from the John W. Hartman Center for Sales, Advertising \& Marketing History at http:// library.duke.edu/digitalcollections/eaa/browse/kodak/.

The refinement tool displays a list of the number of available records within each result under "company," "product," "subject" and "year" revealed in a sidebar adjacent to the larger display of thumbnail images of available object records. Each of those sidebar topics can be clicked upon to revise the search results accordingly.

${ }^{47}$ An overview, examples, and downloadable code for this free image tool can be found at http://www.lokeshdhakar.com/projects/lightbox $2 /$.
} 
could be in keeping with the concept of "fair dealing for the purpose of research or private study" under Part III, Section 29 of the Canadian Copyright Act. ${ }^{48}$

To demonstrate the intent behind the sharing of this material, it may be appropriate for each website page that displays an image representing an object from the collection - whether examples on a collection description page, a listing of search results, or an individual item record - to show or link to a "Fair Dealing" copyright disclaimer. This text should set out the parameters of use for the records and images presented on the site, placing the responsibility for agreement with, and adherence to, the restrictions on the user through his or her act of accessing the material. Further, no print-quality images should be available through the website; rather, any request for such should be submitted to Archives or Special Collections through a website form or other means of direct contact, at which time issues regarding use, copyright and reproduction could be addressed on a case-by-case basis.

These are basic suggestions for protective steps that could be taken regarding the online availability of this material, and are not presented here as legal advice, or as a comprehensive solution. As mentioned above in Chapter 4, it may be helpful for Special Collections to reach an agreement with Kodak Canada Inc. regarding the use and online publication of collection material, so that legal gray areas can be eliminated or clarified, at least in part.

\footnotetext{
${ }^{48}$ Copyright Act ( R.S., 1985, c. C-42) is available online, in the "Justice Laws" section of the website of the Department of Justice Canada, at http://laws.justice.gc.ca/en/showtdm/cs/C-42.
} 


\section{Conclusion}

Over the course of this project, I have catalogued 484 advertisements, and created for each four digital surrogate images in a range of sizes and formats, from preservation master files to small thumbnail images for display on the Internet. In this report, I have presented an historical foundation for the advertising collection through the histories of Kodak Canada Inc. and Ryerson University Library's Special Collections. I have described the methods used to digitize and catalogue the objects, and have included sample records, specification tables, and a suggested website architecture with basic page diagrams. Finally, I have provided a list of more comprehensive resources for the cataloguing and digitization of graphic material that may be of use in future work with this collection, or to others engaged with similar projects.

To this point, the project has spanned approximately five months of part-time work; while this marks the completion of cataloguing and digitization of only two of the thirty-three ledger books in the collection, it represents a formative stage in what I hope will be a comprehensive, ongoing project. It also reflects the natural adjustment process that a project absorbs in adapting to changing circumstances, be they related to available time, equipment or other resources.

Earlier in this report, I estimated that a full-time archivist dedicated to this collection might digitize and catalogue one ledger book in approximately three weeks. This time would vary depending on the number of advertisements in a book, and other factors such as the amount of image editing required. According to this projection, approximately twenty-three months would be needed to complete the work for the thirty-one remaining books in the collection. This should be a generous estimate, given the smaller number of advertisements in later ledger books; 
however, the additional time may be accounted for by the unexpected obstacles of equipment that is booked for other use or in need of repair, or other demands on staff time.

Over the course of the twentieth century, the Eastman Kodak photographic empire has experienced, perhaps, the most publicly recognizable range of change in market influence of any international company, from total domination to an increasingly critical effort to survive on a radically changed playing field. Though Kodak Canada Inc. has diminished from its earlier position of dominance in the Canadian market, its existence and memory still have irrevocable connections to the development of consumer photography, the history of the greater Toronto area, and the story of its parent company and international siblings. When Kodak Canada suffered its cuts and forced obsolescence, its international counterparts underwent similar experiences. In the same way, the Kodak Canada Heritage Collection can be linked with collections of similar material from Kodak Australasia, Kodak UK and Kodak France - all now preserved in other institutions, from George Eastman House in Rochester, New York, to the British Library in London, England, to the Museum Victoria in Melbourne, Australia.

My work with the Kodak Canada advertising collection has materialized at a fortuitous historical moment, as the potential for publicity and recognition for the Kodak Canada Heritage Collection - and Ryerson University Library's Special Collections - is growing. Discussion has begun regarding the establishment of an international Kodak heritage network that would link the custodial institutions that house Kodak archives across the globe, and Special Collections may have an opportunity to take an active role in its formation.

Fiona Kinsey, the Museum Victoria curator who initiated this movement, hopes within the next year or so to establish shared online resources for persons working with the various 
Kodak archives, and to organize an international symposium for the custodial institutions.

Within such a group, there is great potential for sharing information, ideas and resources, and for the facilitation of research between these geographically distant collections working in partnership. Such a network of preservation institutions may, in fact, help keep alive the storied cultural entity of Kodak, at a time when the brand's lowered prosperity has caused it to sacrifice many of its people and much of its production, seemingly without care for the disposition of the material memory that remains. 


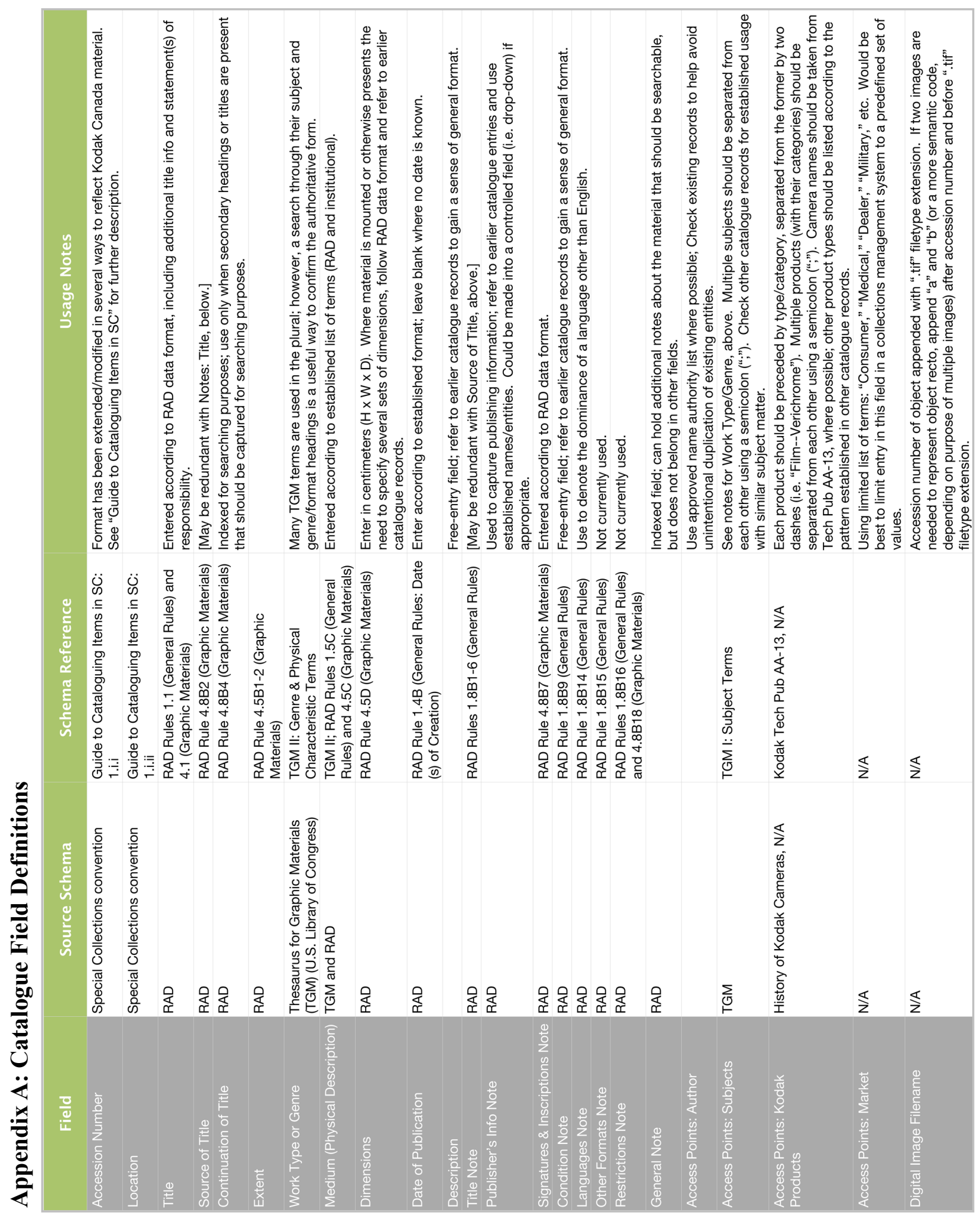




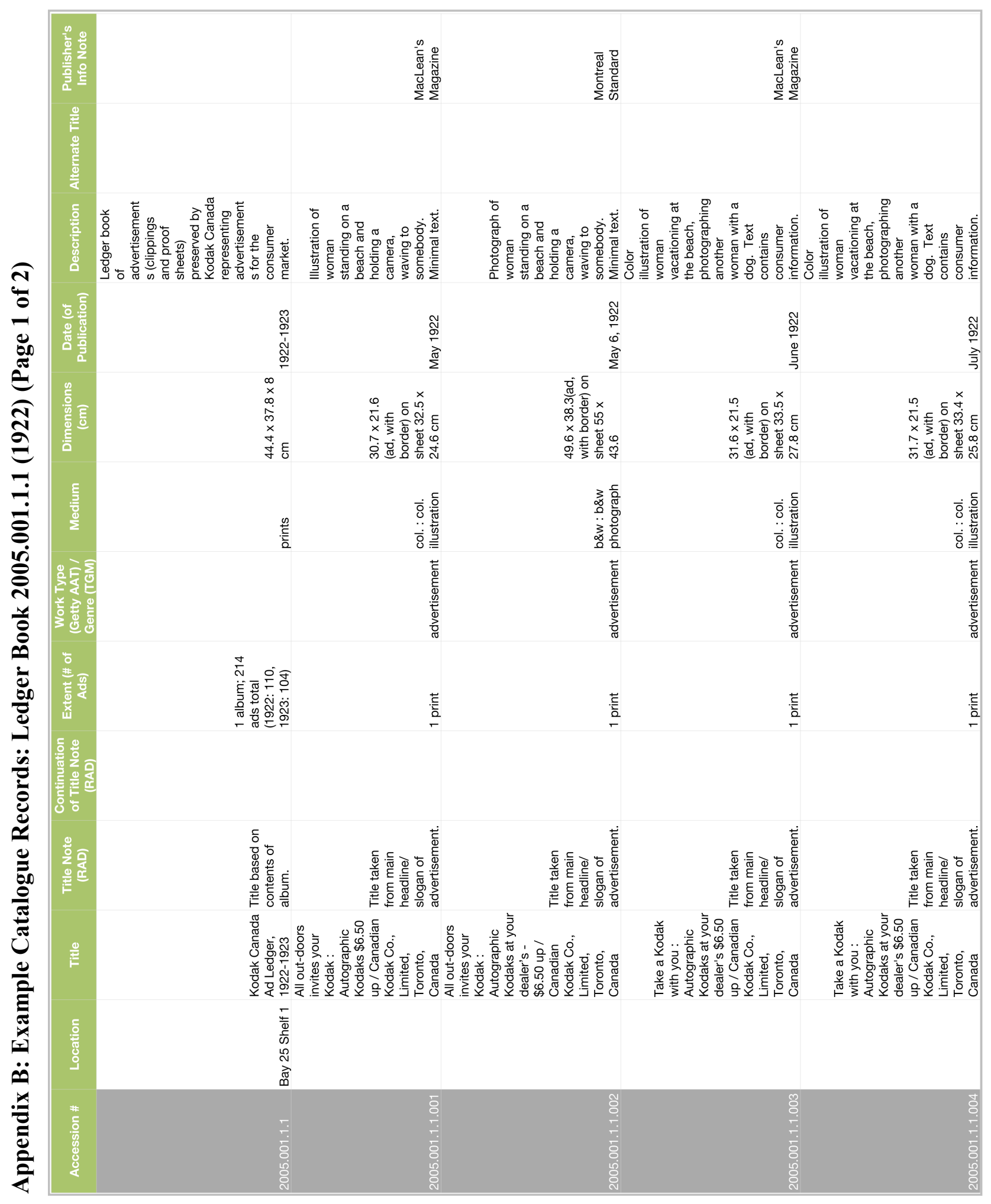




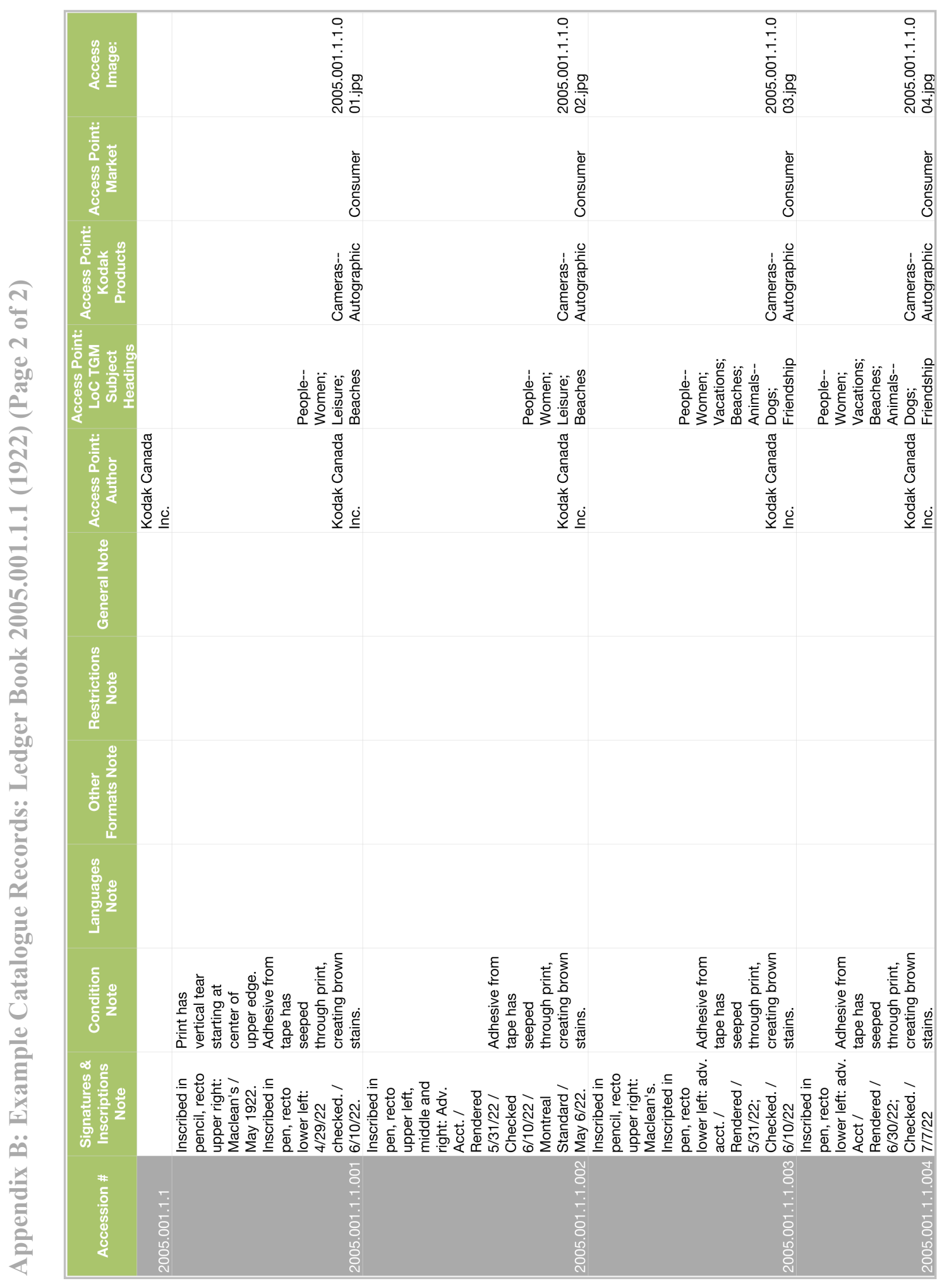




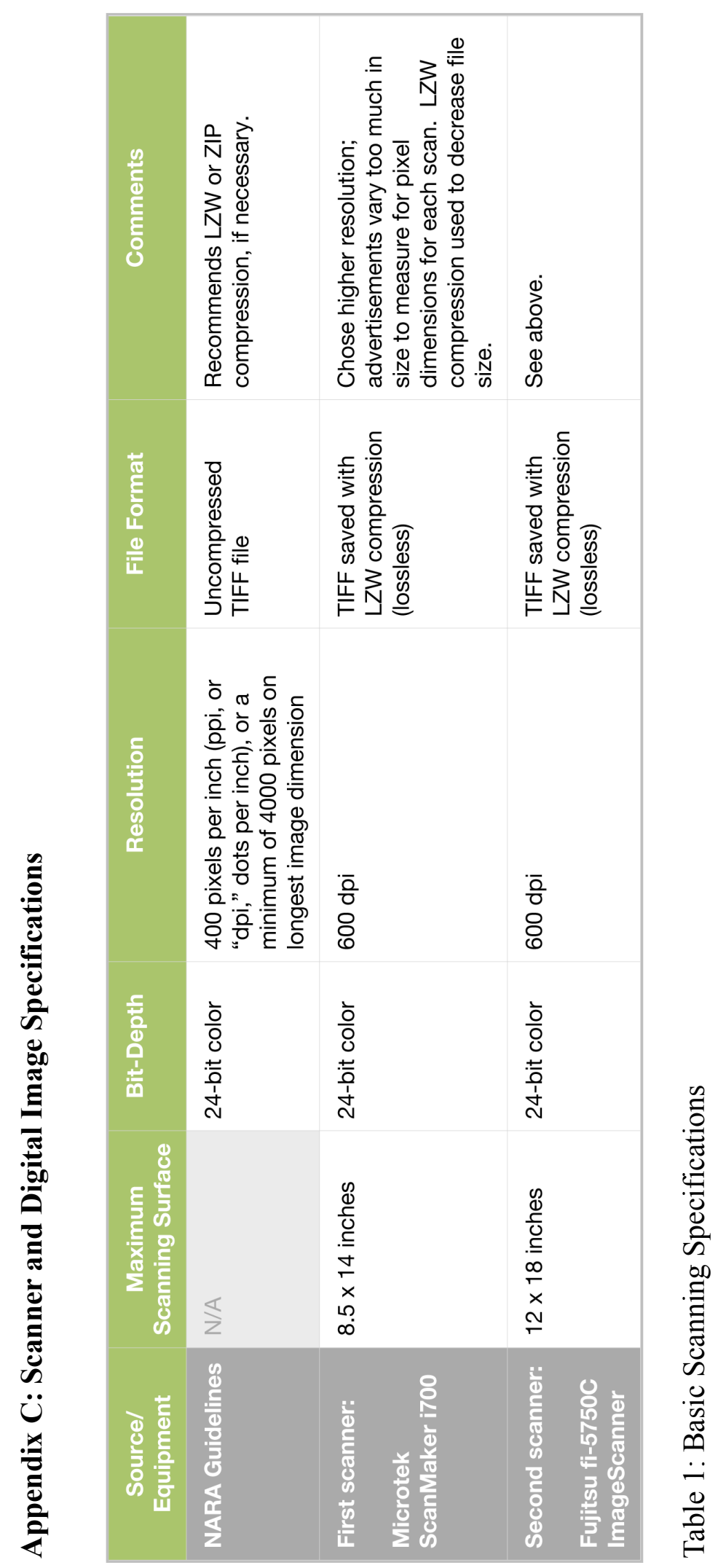




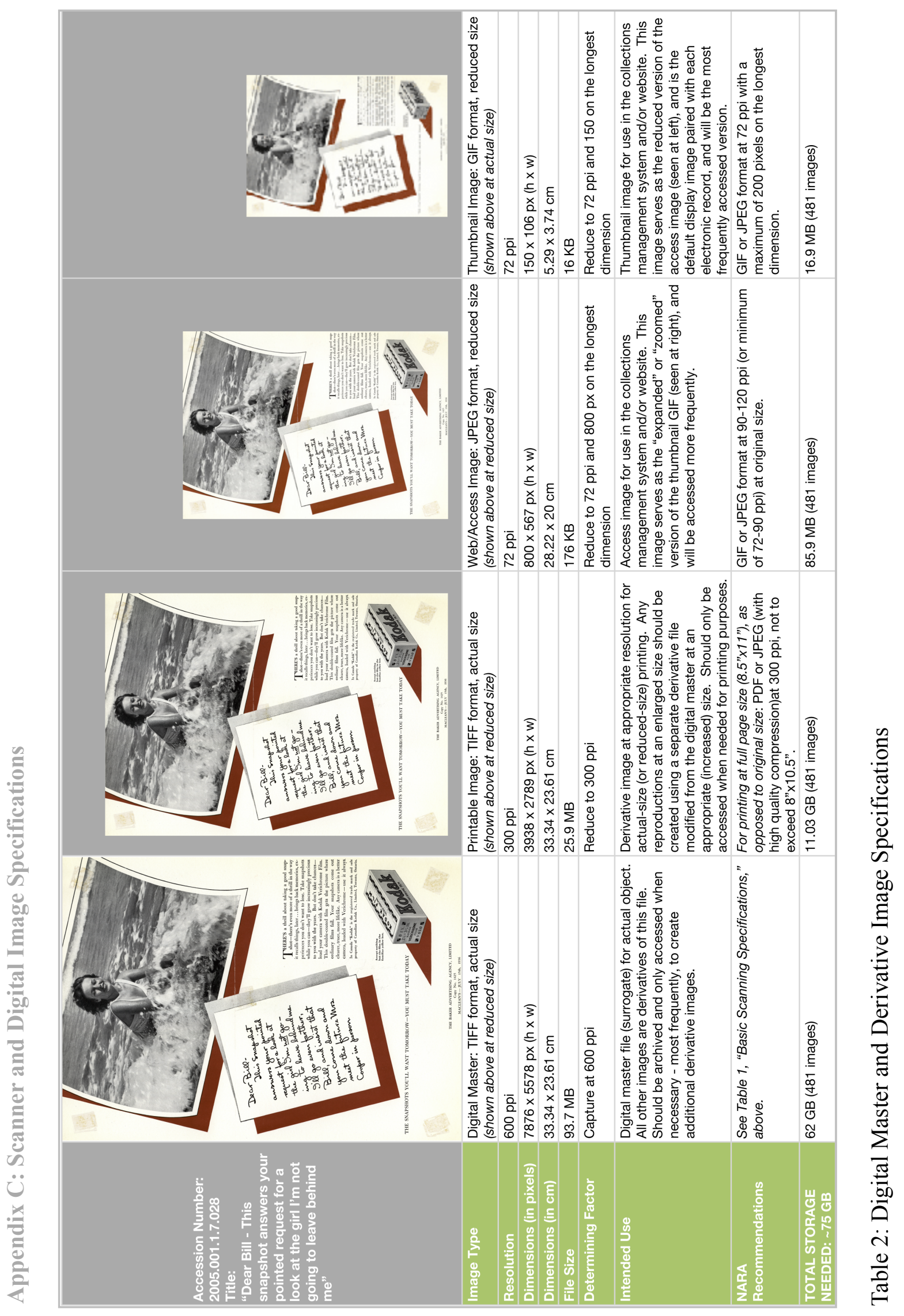




\section{Appendix D: Example Images with Catalogue Records}

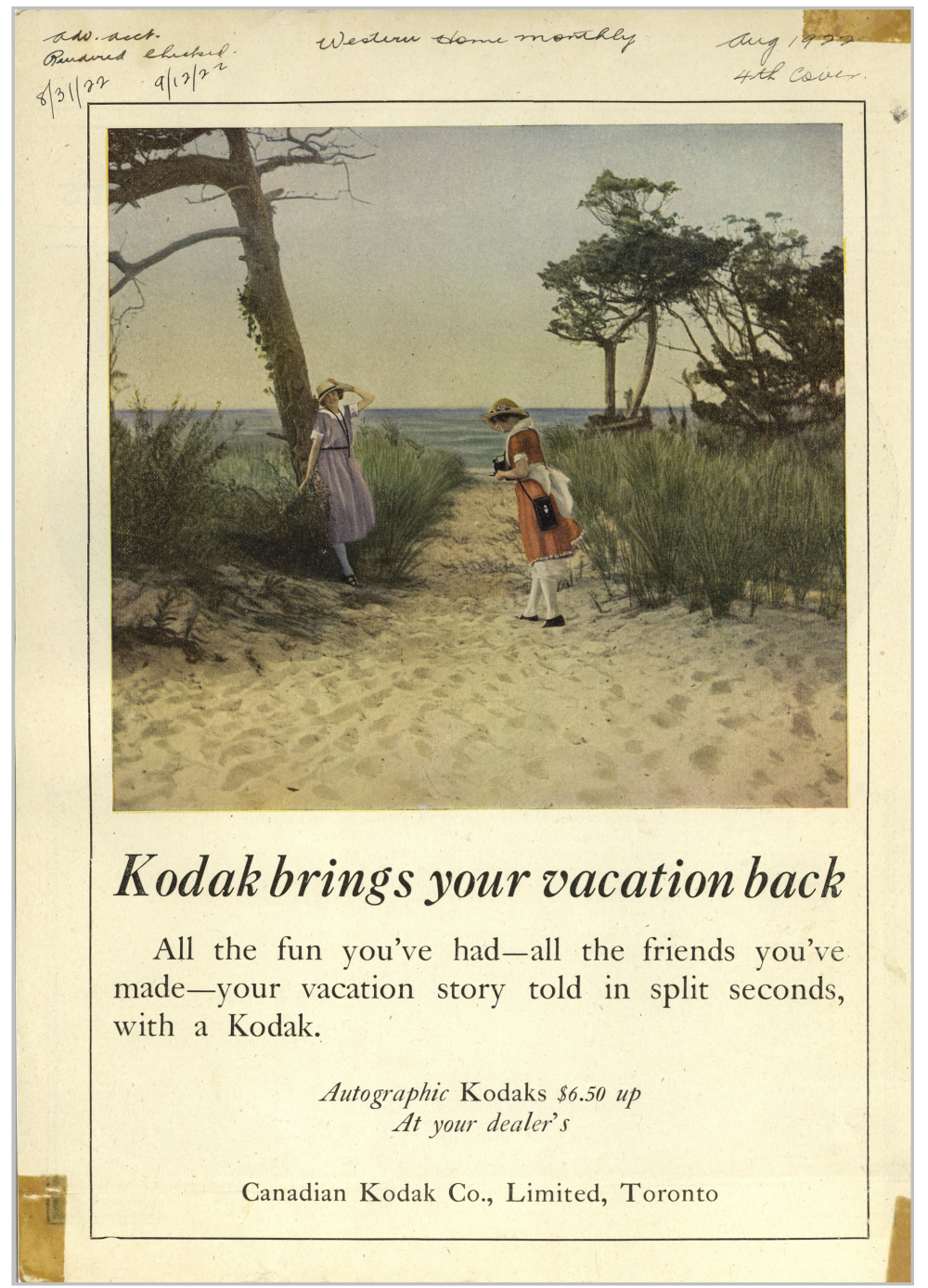

Accession Number: 2005.001.1.1.010

Location: Bay 25 Shelf 1 (Kodak Canada Ad Ledger, 1922-1923)

Title: Kodak brings your vacation back : Autographic Kodaks $\$ 6.50$ up at your dealer's / Canadian Kodak Co., Limited, Toronto

Title Note: Title taken from main headline/slogan of advertisement.

\section{Continuation of Title:}

Extent: 1 print

Work Type/Genre: advertisement

Medium: col. : col. illustration

Dimensions: $31.6 \times 21.5$ (ad, with border) on sheet $35.5 \times 25$

Date (of publication): August 1922

Description: Illustration shows two women on the beach, one leaning against a tree, being photographed by the other. Text is minimal.

\section{Alternate Title:}

Publisher's Info: Western Home Monthly Signatures \& Inscriptions: Inscribed in pen, recto upper: Adv. Acct. / Rendered 8/31/22 / Checked 9/12/22 / Western Home Monthly / Aug 1922 / 4th Cover.

Condition: Adhesive has seeped through print in upper and lower right and lower left corners, creating brown stains; verso shows print was at some point glued to paper along upper edge.

\section{Languages:}

Other Formats:

Restrictions:

General Note:

Access Point: Author: Kodak Canada Inc.

Access Point: TGM Subject Headings: People--Women; Friendship; Leisure; Vacations; Beaches

Access Point: Kodak Products: Cameras--Autographic

Access Point: Market: Consumer

Access Image: 2005.001.1.1.010.jpg 


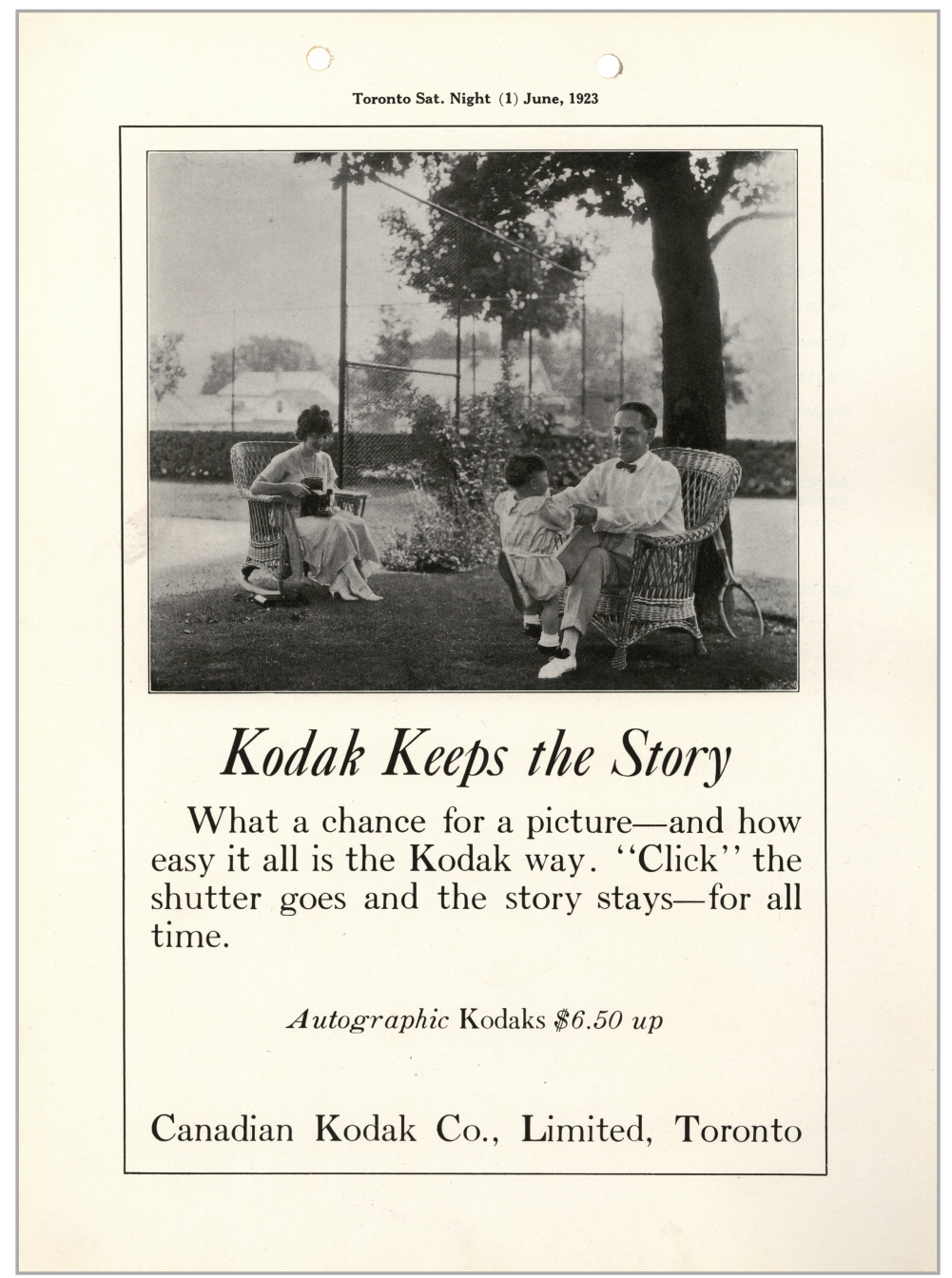

Access Point: Author: Kodak Canada Inc.

Access Point: TGM Subject Headings: Families; Children; Leisure Access Point: Kodak Products: Cameras--Autographic

Access Point: Market: Consumer

Access Image: 2005.001.1.1.149.jpg
Accession Number: 2005.001.1.1.149

Location: Bay 25 Shelf 1 (Kodak Canada Ad Ledger, 1922-1923)

Title: Kodak keeps the story : Autographic Kodaks \$6.50 up / Canadian Kodak Co., Limited, Toronto

Title Note: Title taken from main headline/slogan of advertisement.

Continuation of Title:

Extent: 1 print

Work Type/Genre: advertisement

Medium: b\&w : b\&w photograph

Dimensions: 25.2 x 16.9 (ad, with border) on sheet $30.5 \times 22.3$

Date (of publication): June 1923

Description: Photograph shows a man playing with a child and a woman taking their photograph, both sitting in wicker chairs under a tree.

\section{Alternate Title:}

Publisher's Info: Toronto Saturday Night Signatures \& Inscriptions:

Condition: Two holes are punched through upper edge of print.

\section{Languages:}

Other Formats:

Restrictions:

General Note: 


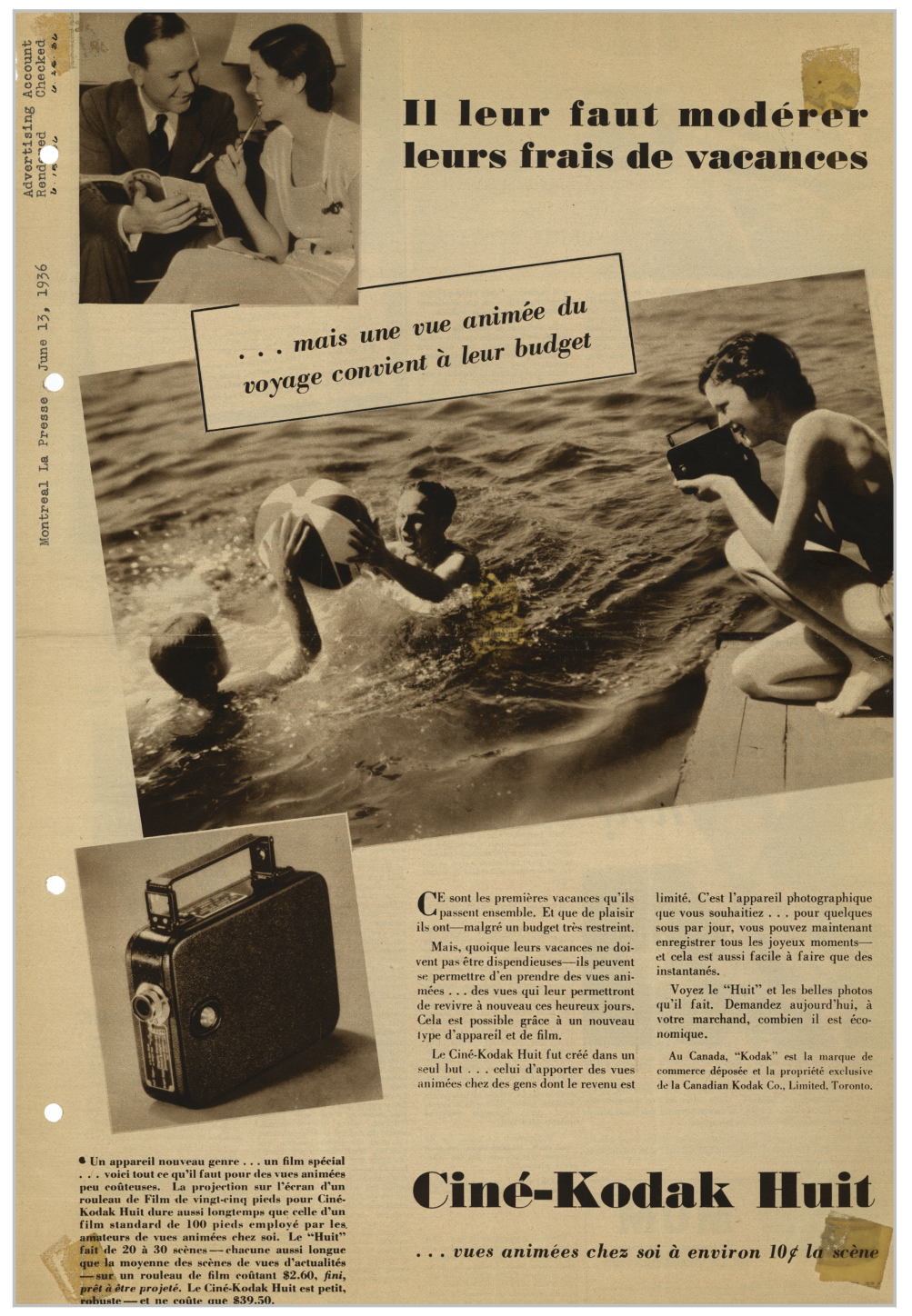

Accession Number: 2005.001.1.7.098

Location: Bay 25 Shelf 1 (Kodak Canada

Ad Ledger, 1936-1937)

Title: II leur faut modérer leurs frais de vacances...mais une vue animée du voyage convient à leur budget

Title Note: Title taken from main headline/slogan of advertisement.

Continuation of Title: Title continues: Ciné-Kodak Huit...vues animées chez soi à environ 10 [cents] la scène.

Extent: 1 print

Work Type/Genre: advertisement

Medium: b\&w : 3 b\&w photographs

Dimensions: $40 \times 27.1$

Date (of publication): June 13, 1936

Description: Two photographs of a couple reading together and playing in the water with another person, and a photograph of the camera being advertised. Text contains consumer information.

Alternate Title: English equivalent: They have to keep their vacation expenses down...but a movie record of the trip fits their budget.

Publisher's Info: Montreal La Presse

Signatures \& Inscriptions: Inscribed in type and pen, recto upper left: Montreal La Presse June 13, 1936 / Advertising Account / Rendered 6.15.36 / Checked 6.25.36.

Condition: Adhesive from tape has seeped through to surface of print, creating brown stains. Four holes are punched down left edge of print.

Languages: French

Other Formats:

Restrictions:

General Note:

Access Point: Author: Kodak Canada Inc.

Access Point: TGM Subject Headings: People--Couples; Swimming; Leisure; Vacations

Access Point: Kodak Products: Cameras--Movie; Cameras--Cine-Kodak Eight

Access Point: Market: Consumer

Access Image: 2005.001.1.7.098.jpg 


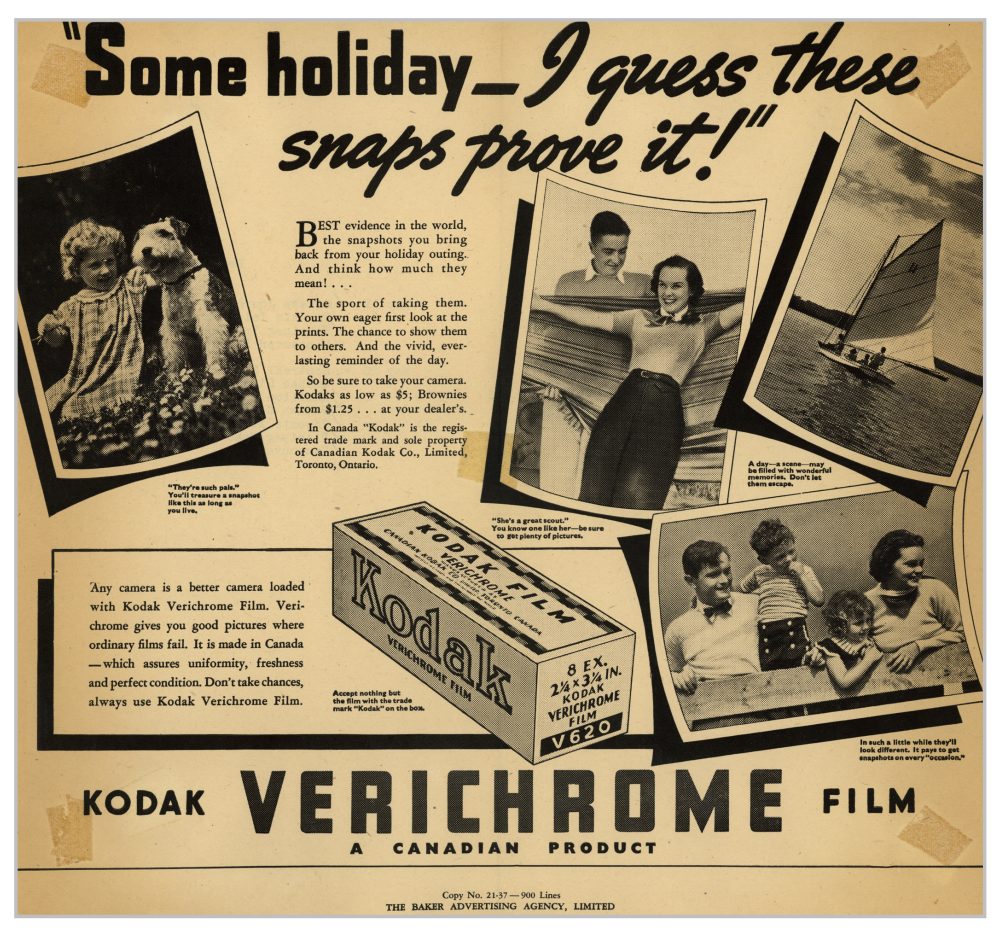

Accession Number: 2005.001.1.7.243

Location: Bay 25 Shelf 1 (Kodak Canada Ad Ledger, 1922-1923)

Title: "Some holiday _ I guess these snaps prove it!" [sic] : Kodak Verichrome film - a Canadian product / The Baker Advertising Agency, Limited

Title Note: Title taken from main headline/slogan of advertisement.

\section{Continuation of Title:}

Extent: 1 print

Work Type/Genre: advertisement

Medium: b\&w : 4 b\&w photographs and b\&w illustration

Dimensions: 28.6 × 31.1

Date (of publication): May 19, 1937

Description: Four photographs of adults and children sailing, playing with a dog, and standing at a fence, and illustration of Verichrome film box. Text contains captions for each photograph and consumer information.

\section{Alternate Title:}

Publisher's Info: Ottawa Journal; Toronto Telegram; Winnipeg Tribune; Vancouver Province; Montreal Star; Quebec L'Action Catholique; Hamilton Spectator; Ottawa Citizen; Toronto Star; Winnipeg Free press; Vancouver Sun

Signatures \& Inscriptions: Inscribed in type and pencil, verso: Newspaper Ad No. 21 / May 19 [checkmark] Ottawa Journal / [checkmark] Toronto Telegram /[checkmark] Winnipeg Tribune / [checkmark] Vancouver Province [checkmark] May 20[checkmark] Montreal Star /[checkmark] Quebec L'Action Catholique /[checkmark] Hamilton Spectator chp. /[checkmark] Ottawa Citizen poor pos. /[checkmark] Toronto Star /[checkmark] Winnipeg Free Press /[checkmark] Vancouver Sun.

Condition: Adhesive seeped has through to surface of print, and has begun to create brown stains.

\section{Languages:}

Other Formats:

\section{Restrictions:}

General Note: Advertising account information labels this "Copy No. 21-37."

Access Point: Author: Kodak Canada Inc.

Access Point: TGM Subject Headings: Couples; Families; Children; Animals--Dogs; Boats;

Photographs--Snapshots

Access Point: Kodak Products: Films--Verichrome

Access Point: Market: Consumer

Access Image: 2005.001.1.7.243.jpg 


\section{Appendix E: Suggested Website Architecture and Page Mockups}

\section{Suggested Website Information Architecture}
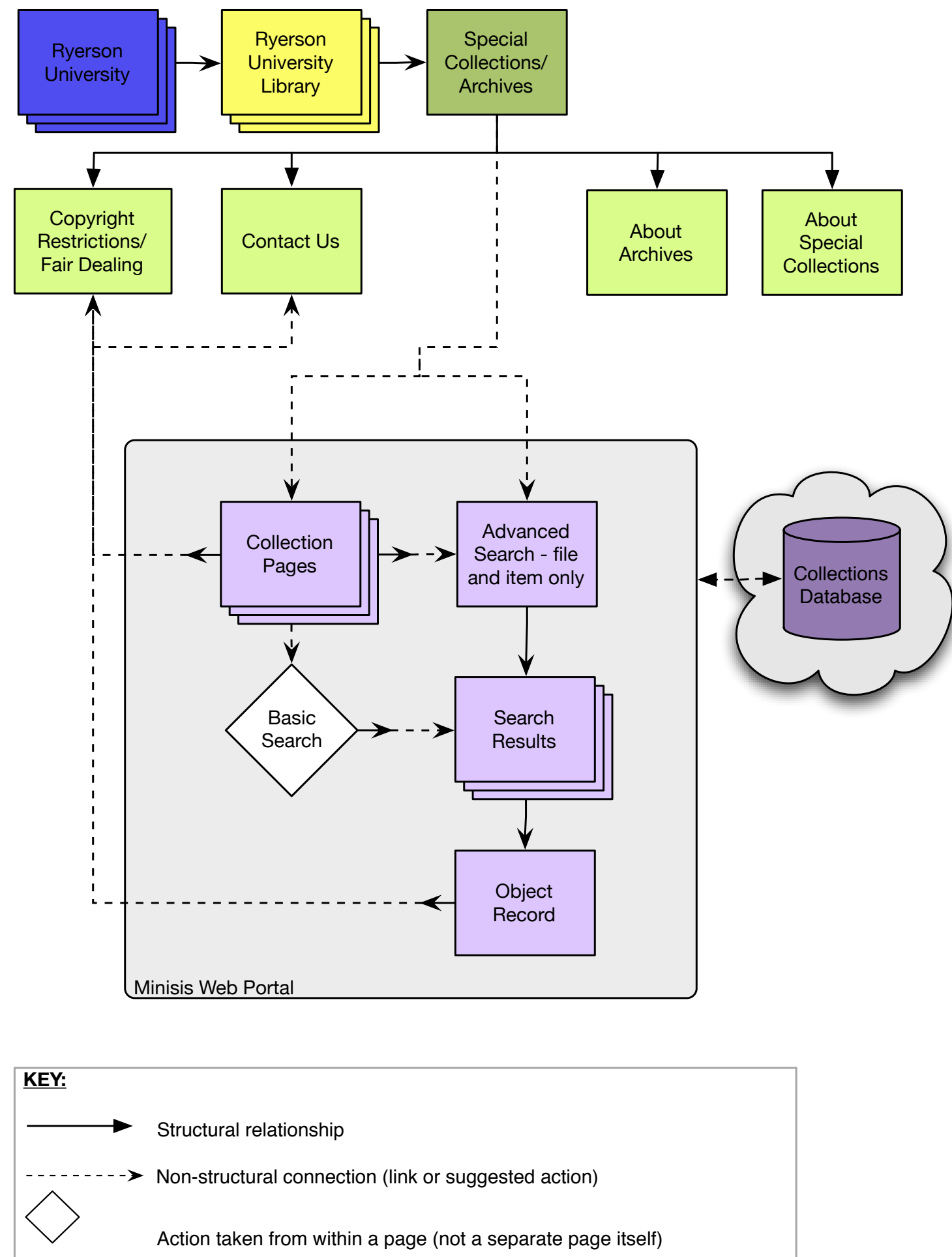
Appendix E: Suggested Website Architecture and Page Wireframes

\section{Wireframe: Archives and Special Collections Home Page}

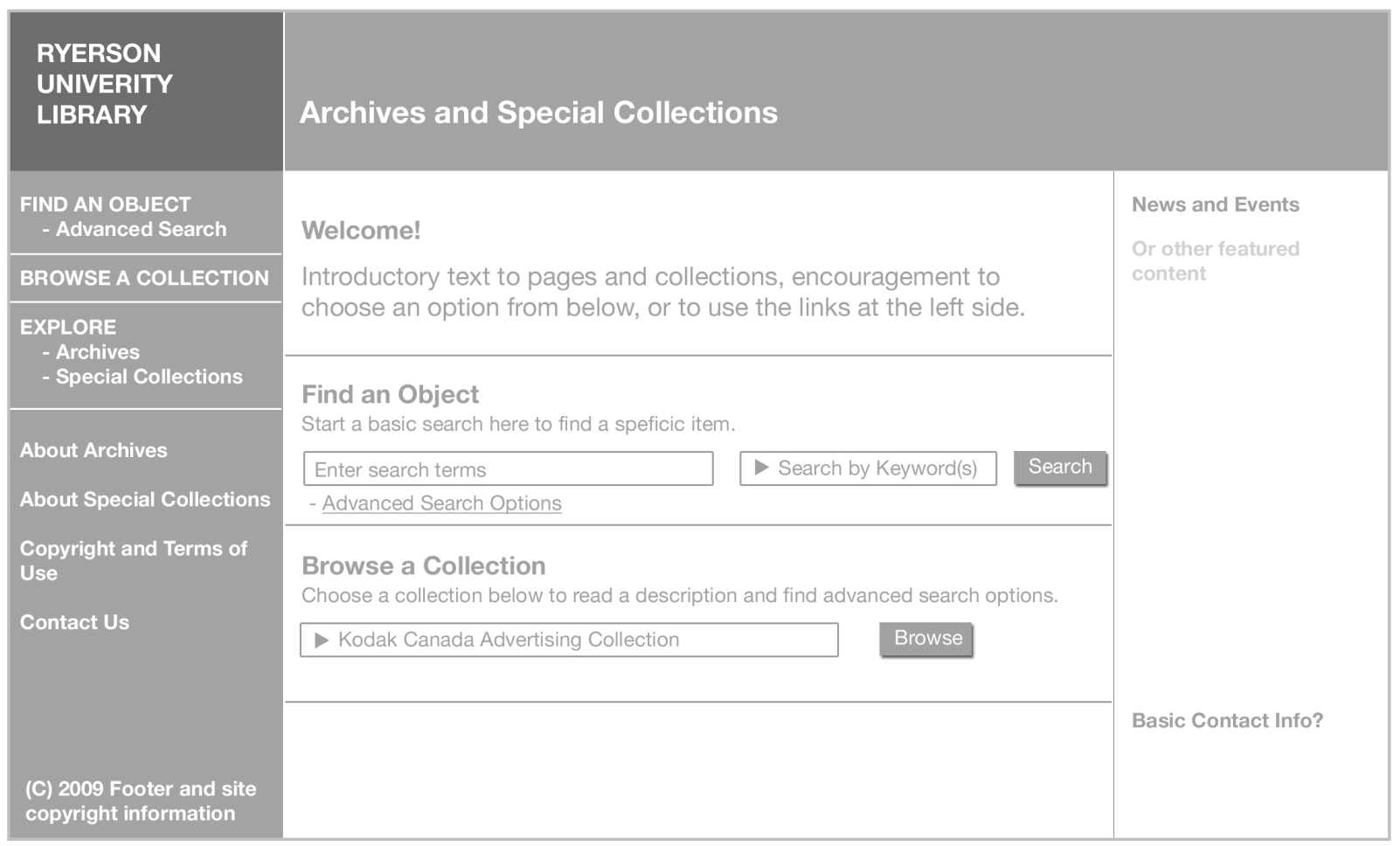

\section{Wireframe: Kodak Canada Advertising Collection Page}

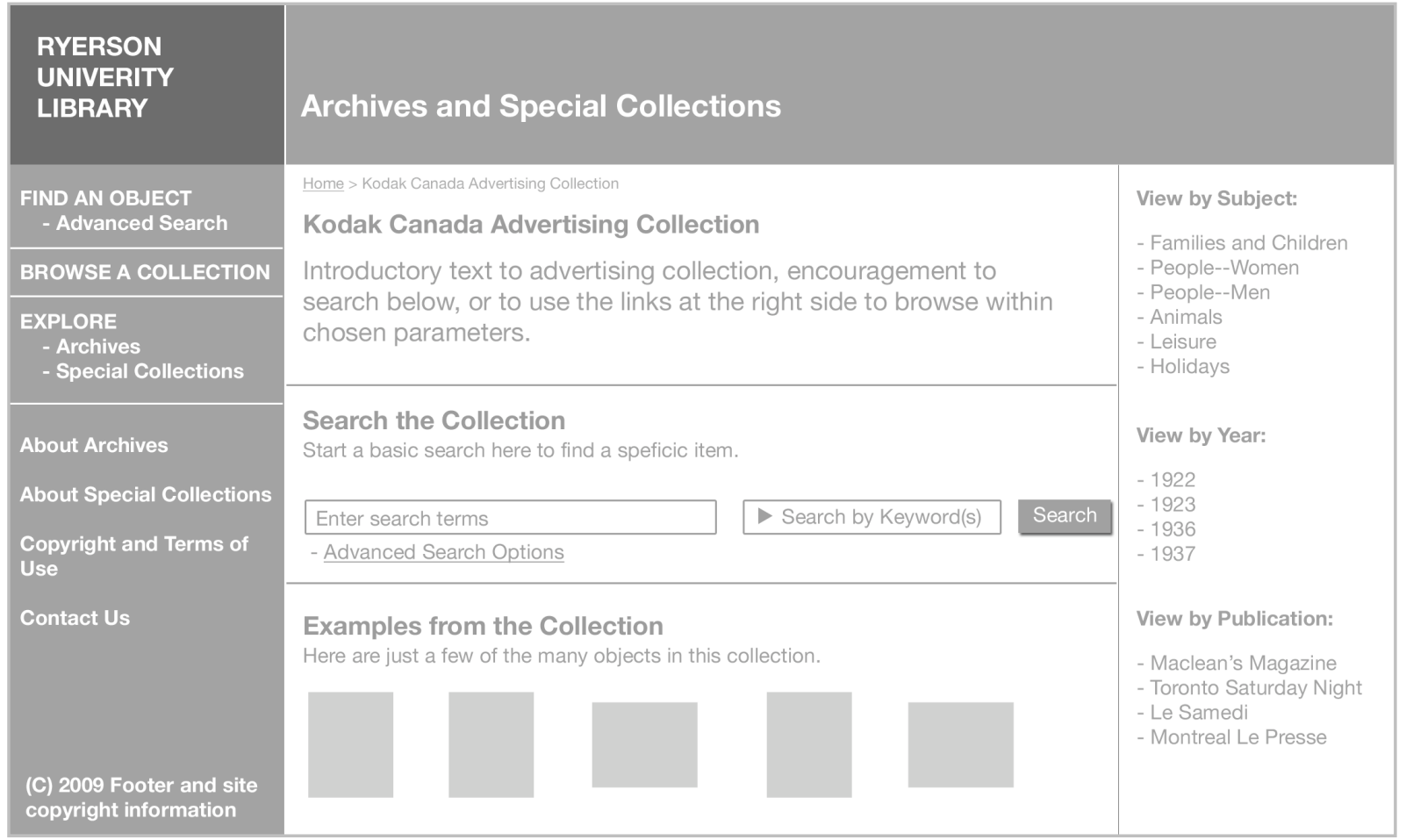


Appendix E: Suggested Website Architecture and Page Wireframes

\section{Wireframe: Kodak Canada Advertising Object Page}

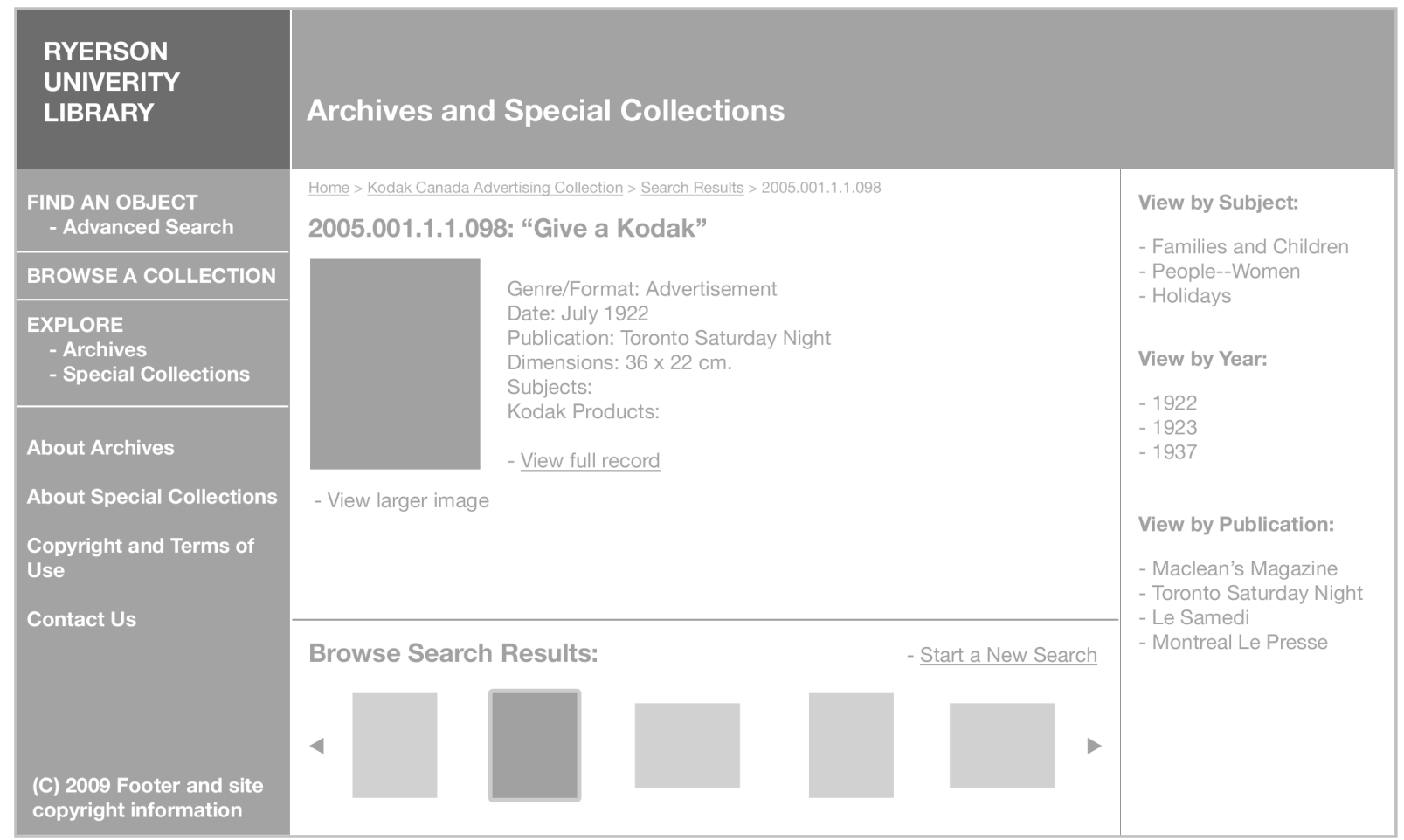




\section{Bibliography}

“A Big Print and a Strong Urge.” The Kodak Salesman Vol. 8 No. 11 (December 1922): 4.

“About Ourselves.” The Kodak Salesman Vol. 8 No. 6 (July 1922): 15-16.

Associated Press. "Kodak Cuts 2,500 Jobs to Sustain Profit Growth.” Kitchener-Waterloo Record, July 22, 1999.

Bozikovic, Alex. "The End of Photography Drive: A City Landmark, and an Industry, Fade Out." The Globe and Mail, August 25, 2007.

Bureau of Canadian Archivists. Canadian Archival Standard: Rules for Archival Description (Ottawa: Bureau of Canadian Archivists, 1990 and 2008). Available as a downloadable PDF file at http://www.cdncouncilarchives.ca/archdesrules.html (accessed July 2009).

Erwin, Steve and John Valorzi. "Kodak Canada Closing Toronto Factory." The Toronto Star, December 10, 2004.

"Kodak Advertising and the Almanac." The Kodak Salesman Vol. 8 No. 3 (April 1922): 3-4.

“Kodak and the Christmas Spirit." The Kodak Salesman Vol. 8 No. 11 (December 1922): 3.

McDonald, Jessica, Kelly Thielen, Siobhan Creem and Dee Psaila. A Report: The Kodak Canada Archive and Heritage Collection at Ryerson University (Toronto: Ryerson University, 2005).

Morrison, R.G. (Bud). “The History of Kodak Canada Ltd.” Photographic Canadiana Vol. 1 No. 7 (1976): 1-3.

Morrison, R.G. (Bud). "The History of Kodak Canada Ltd. - Concluded.” Photographic Canadiana Vol. 1 No. 8 (1976): 4-6.

“Mr. John G. Palmer.” The Kodak Salesman Vol. 7 No. 8 (September 1921): 3-4.

Pope, Daniel. The Making of Modern Advertising. New York: Basic Books, 1983.

Theobald, Steven. “Kodak Canada Cuts 93 Jobs from Payroll.” The Toronto Star, December 3, 1997.

Theobald, Steven. "Kodak Plans to Slash 10,000 Jobs." The Toronto Star, November 12, 1997. 
Wodtke, Christina and Austin Govella. Information Architecture: Blueprints for the Web. Berkeley, CA: New Riders, 2009. 


\section{Websites and Online Resources}

About Kodak. "History of Kodak: Milestones - Chronology." Kodak. http://www.kodak.com/ global/en/corp/historyOfKodak/chronology.jhtml?pq-path=2217/2687/2695 (accessed May 2009).

Bureau of Canadian Archivists' Planning Committee on Descriptive Standards. "Rules for Archival Description." Canadian Council of Archives. http://www.cdncouncilarchives.ca/archdesrules.html (accessed May 2009).

California Digital Library. “CDL Guidelines for Digital Images.” California Digital Library. http://www.cdlib.org/inside/diglib/guidelines/bpgimages/ (accessed June 2009).

Justice Laws. “Copyright Act ( R.S., 1985, c. C-42 ).” Department of Justice Canada. http://laws.justice.gc.ca/en/showtdm/cs/C-42 (accessed July 2009).

Customer Service Information: Technical Data. "Kodak Tech Pub AA-13." Kodak. http://www.kodak.com/global/en/consumer/products/techInfo/aa13/aa13.shtml (accessed May 2009).

Digital Collections. "Ellis Collection of Kodakiana." Duke University Libraries. http://library.duke.edu/digitalcollections/eaa/browse/kodak/ (accessed May 2009).

Eastman Legacy Collection. "Kodak Advertising Collection.” George Eastman House International Museum of Photography and Film. http://www.eastmanhouse.org/inc/collections/Kodak-collection.php (accessed June 2009).

Electronic Records Program. "Digitization Standards for Images." Smithsonian Institution Archives. http://siarchives.si.edu/records/records_erecords_digitization_images.html (accessed June 2009).

Prints and Photographs Division. "Thesaurus for Graphic Materials I: Subject Terms." Library of Congress. http://www.loc.gov/rr/print/tgm1/ (accessed May 2009).

Prints and Photographs Division. "Thesaurus for Graphic Materials II: Genre and Physical Characteristic Terms." Library of Congress. http://www.loc.gov/rr/print/tgm2/ (accessed May 2009).

U.S. National Archives and Records Administration (NARA). "Technical Guidelines for Digitizing Archival Materials for Electronic Access." NARA. http://www.archives.gov/preservation/technical/guidelines.pdf. (accessed June 2009). 